\title{
Stimulation of the neurotrophin receptor TrkB on astrocytes drives nitric oxide production and neurodegeneration
}

\author{
Emanuela Colombo, ${ }^{1}$ Chiara Cordiglieri, ${ }^{1,2}$ Giorgia Melli, ${ }^{3}$ \\ Jia Newcombe, ${ }^{4}$ Markus Krumbholz, ${ }^{5,6}$ Luis F. Parada, ${ }^{7}$ Enzo Medico, ${ }^{8}$ \\ Reinhard Hohlfeld, ${ }^{5,6}$ Edgar Meinl, ${ }^{5,6}$ and Cinthia Farina ${ }^{1,2}$ \\ IInstitute of Experimental Neurology, San Raffaele Scientific Institute, 20132 Milan, Italy \\ ${ }^{2}$ Neuroimmunology and Neuromuscular Disorders Unit and ${ }^{3} U n$ it of Genetics of Neurodegenerative and Metabolic Diseases, \\ Foundation IRCCCS-Neurological Institute Carlo Besta, 20133 Milan, Italy \\ ${ }^{4}$ NeuroResource, University College London Institute of Neurology, London WC1N 3BG, England, UK \\ ${ }^{5}$ Max Planck Institute of Neurobiology, 82152 Martinsried, Germany \\ ${ }^{6}$ Institute for Clinical Neuroimmunology, Ludwig-Maximilians University, 80539 Munich, Germany \\ ${ }^{7}$ Center for Developmental Biology, University of Texas at Dallas, Dallas, TX 75080 \\ 8Institute for Cancer Research and Treatment, 10060 Torino, Italy
}

Neurotrophin growth factors support neuronal survival and function. In this study, we show that the expression of the neurotrophin receptor TrkB is induced on astrocytes in white matter lesions in multiple sclerosis (MS) patients and mice with experimental autoimmune encephalomyelitis (EAE). Surprisingly, mice lacking TrkB specifically in astrocytes were protected from EAE-induced neurodegeneration. In an in vitro assay, astrocytes stimulated with the TrkB agonist brain-derived neurotrophic factor (BDNF) released nitric oxide (NO), and conditioned medium from activated astrocytes had detrimental effects on the morphology and survival of neurons. This neurodegenerative process was amplified by NO produced by neurons. NO synthesis in the central nervous system during EAE depended on astrocyte TrkB. Together, these findings suggest that TrkB expression on astrocytes may represent a new target for neuroprotective therapies in MS.

\section{CORRESPONDENCE}

Cinthia Farina:

farina.cinthia@hsr.it

Abbreviations used: ACM, astrocyte-conditioned medium; APP, Alzheimer precursor protein; BDNF, brain-derived neurotrophic factor; CNS, central nervous system; DAB, diaminobenzidine; EAE, experimental autoimmune encephalomyelitis; ECD, extracellular domain; GFAP, glial fibrillary acidic protein; iNOS, inducible NO synthase; L-NAME, L-nitroarginine methyl ester MFI, mean fluorescence intensity; MOG, myelin oligodendrocyte glycoprotein; MS, multiple sclerosis; PFA, paraformaldehyde; TK, tyrosine kinase; TUNEL, Tdt-mediated dUTP-biotin nick end labeling.
The neurotrophins are a family of secreted growth factors consisting of nerve growth factor, brain-derived neurotrophic factor (BDNF), NT3 (neurotrophin 3), and NT4. Although initially described in the nervous system, they regulate processes such as cell survival, proliferation, and differentiation in several other compartments, e.g., the immune and the muscular system (Berzi et al., 2008; Colombo et al., 2011a,b). Normally secreted by neurons and glia cells, the neurotrophins exert a wide range of functions important for the development and maintenance of the vertebrate nervous system, as they control neuronal differentiation and survival and modulate synaptic structure and plasticity (Reichardt, 2006; Cohen and Greenberg, 2008). Neurotrophin signaling is mediated by the p75NTR receptor, which is a member of the tumor necrosis factor receptor superfamily, by the tyrosine kinase (TK) Trk

$\overline{\text { E. Colombo and C. Cordiglieri contributed equally to this paper. }}$ membrane receptors, or by p75NTR-Trk receptor heterodimers. Truncated Trk isoforms lacking the TK domain occur in nature and can signal after ligand binding (Baxter et al., 1997; Rose et al., 2003; Ohira et al., 2005).

Astrocytes can express neurotrophin receptors (Wang et al., 1998), but the outcome of neurotrophin signaling in this cell type is still unclear. Astrocytes endow neurons with trophic and metabolic support and regulate dendritic growth and axon guidance (Blackburn et al., 2009). They promptly react to central nervous system (CNS) insults by forming the scar tissue (Sofroniew, 2009), and dysregulation of their activity can have detrimental effects on CNS function. Although activated astrocytes can support neuroprotection, e.g., by release of neurotrophic

2012 Colombo et al. This article is distributed under the terms of an Attribution-Noncommercial-Share Alike-No Mirror Sites license for the first six months Attribution-Noncommercial-Share Alike-No Mirror Sites license for the first six months
after the publication date (see http://www.rupress.org/terms). After six months it is available under a Creative Commons License (Attribution-NoncommercialShare Alike 3.0 Unported license, as described at http://creativecommons.org/ licenses/by-nc-sa/3.0/) 
factors (Stadelmann et al., 2002), they also participate in inflammatory reactions, producing cytokines and chemokines (Farina et al., 2007; Cordiglieri and Farina, 2010).

In the present study, we report the marked up-regulation of the TrkB receptor on astrocytes in experimental autoimmune encephalomyelitis (EAE) and multiple sclerosis (MS) lesions. Importantly, transgenic animals lacking astrocyte TrkB were protected from the neurodegeneration associated with EAE. So we explored in vitro the effects of neurotrophins on astrocyte-neuron interactions using live imaging techniques. Surprisingly, soluble factors released by astrocytes as a result of TrkB signaling induced neuronal degeneration and apoptosis. Finally, we identified nitric oxide (NO) as the key neurotoxic molecule released from activated astrocytes after TrkB engagement in vitro and in vivo.

\section{RESULTS}

Depletion of astrocyte TrkB protects mice from $E A E$ and neurodegeneration

After EAE induction with myelin oligodendrocyte glycoprotein $(\mathrm{MOG})_{35-55}$ peptide, C57BL/6 mice showed a marked increase in TrkB expression in inflamed white matter of the spinal cord compared with naive mice (Fig. 1, A and B). Double immunofluorescence and confocal imaging demonstrated that astrocytes (positively stained for glial fibrillary acidic protein [GFAP]) strongly up-regulated TrkB in immunized animals (Fig. 1, C and D). Staining with an antibody directed to the truncated TrkB isoform commonly expressed in glial cells (Rose et al., 2003; Ohira et al., 2005; Dorsey et al., 2006) confirmed massive TrkB-T1 expression in astrocytes in EAE animals (Fig. 1, E and F).

A

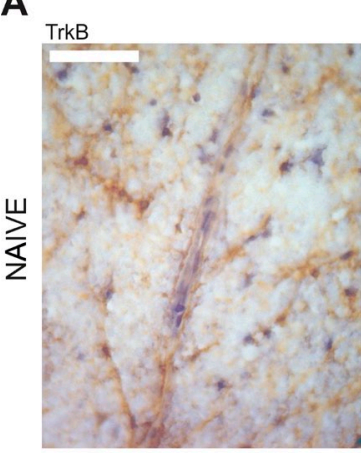

B

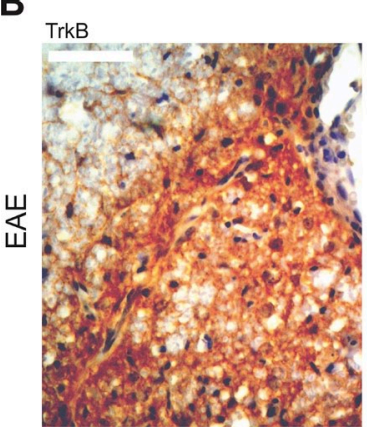

c

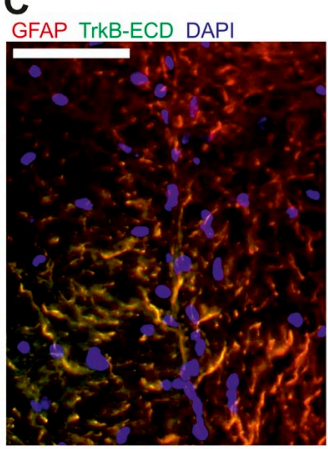

D

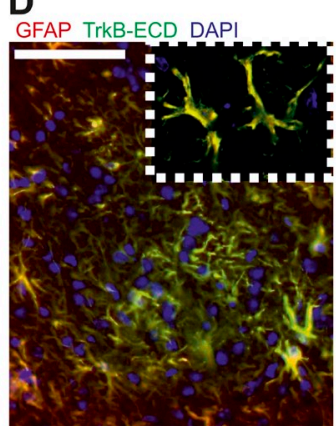

To analyze the contribution of astrocyte TrkB to neuroinflammation, we performed EAE experiments in double transgenic mice, in which TrkB was excised specifically in GFAP-positive cells (GFAP-cre:TrkBflox/flox mice; Luikart et al., 2005). Cre recombination in the spinal cord of transgenic mice was efficient (Fig. 2, A-D), as indicated by the staining for the reporter gene $\beta$-gal and by the lack of TrkB on astrocytes in naive (Fig. 2 A) and EAE (Fig. 2 B) animals. TrkB depletion was specific to astrocytes, as other cell types such as infiltrating immune cells expressed the neurotrophin receptor (Fig. 2 B, right). GFAP levels in naive and EAE $\mathrm{KO}$ animals were comparable with those in control littermates (not depicted), indicating that expression of hGFAP-cre does not exert detectable toxic effects on the formation of white matter astrocytes. Likewise, EAE expression in hGFAP-cre single transgenic mice is comparable with that in wild-type animals (Haroon et al., 2011). Quantification of TrkB-T1 signal on astrocytes confirmed the up-regulation in control EAE animals and the lack of expression in double transgenic animals (Fig. 2 D). Compared with control TrkBflox/flox littermates, conditional KO mice showed ameliorated disease (Fig. 2, E and F), which did not result from abnormal primary immune responses, as the in vitro proliferation rate to $\mathrm{MOG}_{35-55}$ peptide of both spleen and lymph node cells was similar in immunized $\mathrm{KO}$ and control mice (Fig. 2 G). Histopathological experiments showed that immune cell infiltration was almost halved $(208 \pm 18$ vs. $386 \pm 4$ cells $/ \mathrm{mm}^{2} ; \mathrm{P}<0.01$; Fig. 3 A) in the spinal cord of $\mathrm{KO}$ mice compared with control littermates. Characterization of inflammatory infiltrates indicated $50-70 \%$ reduction in CD4 $\mathrm{T}$ lymphocytes, B cells, and macrophages in GFAP-cre:TrkBflox/flox mice (Fig. 3, B-D). However, a more dramatic effect was seen on neurodegeneration, as it was $>90 \%$ reduced $(6 \pm 2$ vs. $123 \pm 12$ Alzheimer precursor protein $[\mathrm{APP}]-$ positive cells $/ \mathrm{mm}^{2}$ in $\mathrm{KO}$ vs. control EAE mice; $\mathrm{P}<0.05$; Fig. 3 E). Interestingly, in conditional $\mathrm{KO}$ mice, there were very few degenerating axons despite inflammation (Fig. 3 F). These experiments indicate a detrimental role for astrocyte TrkB in neuroinflammation and, most significantly, in neurodegeneration.

\section{$\mathbf{F}$}

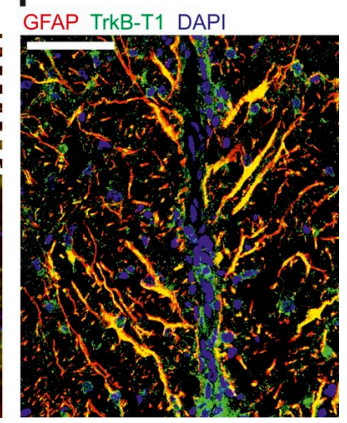

Figure 1. EAE lesions are characterized by enhanced astrocyte TrkB. (A and B) Immunohistochemistry for TrkB (brown staining, DAB; counterstaining, hematoxylin) in naive $(A)$ and EAE (B) mouse spinal cord. (C-F) Double immunofluorescence for GFAP and the ECD of TrkB (TrkB-ECD in C and D) or the isoform TrkB-T1 ( $E$ and $F$ ) in naive ( $C$ and $E$ ) and EAE ( $D$ and $F$ ) mice. DAPI was used to stain for nuclei. Representative stainings of two naive mice and four EAE mice from two independent EAE experiments are shown. Inset at higher magnification (100x objective, one z plane) shows colocalization. Bars, $50 \mu \mathrm{m}$. 
A TrkBflox/flox

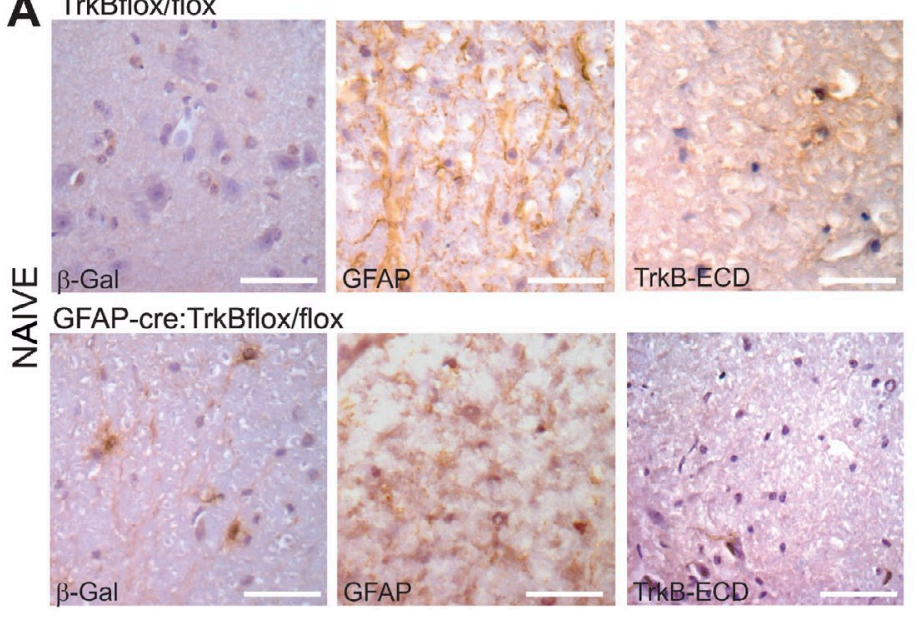

B GFAP-cre:TrkBflox/flox
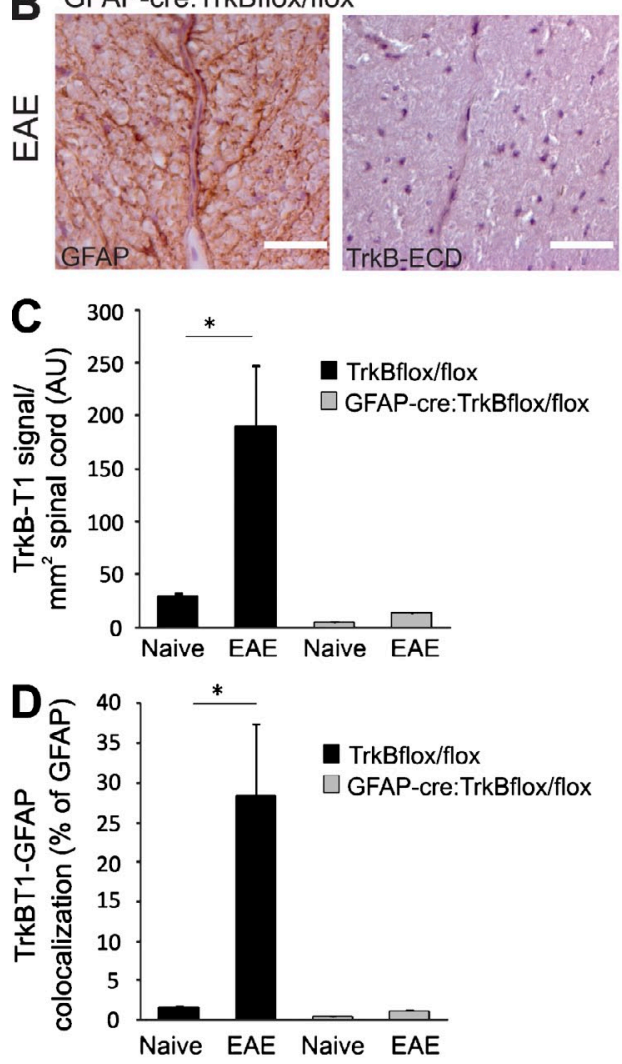

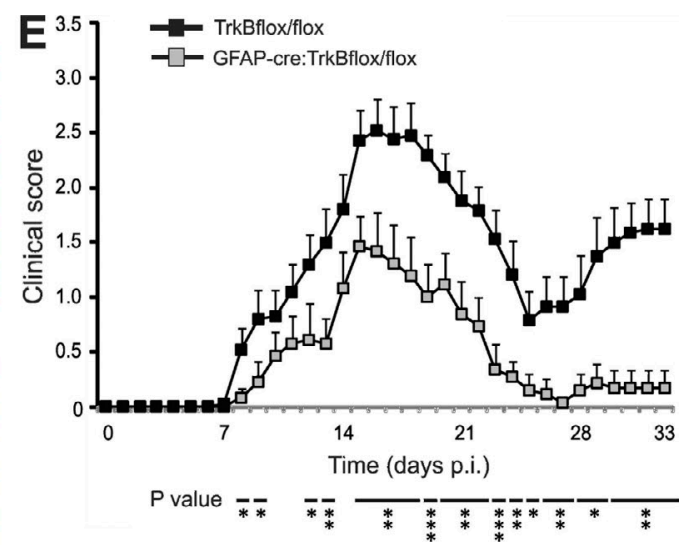

\begin{tabular}{l|c|c|c}
$\mathbf{F}$ & GFAP-cre: & \\
\hline Incidence & $100 \%(20 / 20)$ & $68 \%(13 / 19)$ & $<0.01$ \\
Max weight loss (\%) & $14.4 \pm 4$ & $11 \pm 4$ & n.s. \\
Onset (days p.i.) & $9 \pm 1.7$ & $12 \pm 1.3$ & $<0.01$ \\
Max Score & $2.8 \pm 0.3$ & $2.1 \pm 0.3$ & $<0.001$ \\
Score at peak & $2.5 \pm 0.5$ & $1.5 \pm 0.5$ & $<0.01$ \\
C.D.I. & $29.2 \pm 7.2$ & $13.8 \pm 5$ & $<0.001$
\end{tabular}
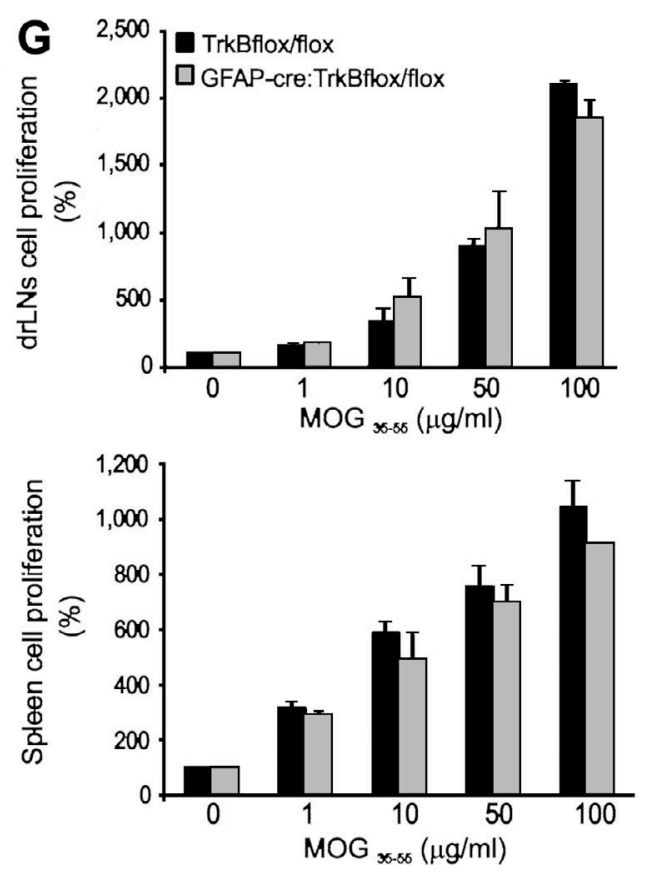

Figure 2. Double transgenic mice lacking TrkB in GFAP+ cells are protected from EAE. (A) TrkB depletion in astrocytes in GFAP-cre:TrkBflox/ flox mice. Immunohistochemistry for $\beta$-galactosidase ( $\beta$-Gal; left), GFAP (middle), and TrkB (right) in the spinal cord of TrkBflox/flox (top) and GFAPcre:TrkBflox/flox (bottom) naive mice (brown staining with DAB and hematoxylin counterstaining). (B) Immunohistochemistry for GFAP (left) and TrkB (middle) and double immunofluorescence (right) in the spinal cord of GFAP-cre:TrkBflox/flox EAE mice. DAPI was used to stain for nuclei. Arrows indicate TrkBpositive immune cells. (A and B) The antibody directed to the ECD of TrkB (Cell Signaling Technology) was used. Bars, $50 \mu m$. (C) Quantification of TrkB-T1 immunoreactivity in spinal cord white matter of naive and EAE mice. AU, arbitrary units. (D) Colocalization between TrkB-T1 and GFAP in naive and EAE mice. Data are given as mean percentage of GFAP signal. (C and D) Four mice/group from two independent EAE experiments and two naive mice/group were analyzed. Error bars represent SEM. (E) EAE disease course. Clinical expression of $\mathrm{MOG}_{35-55}$-induced EAE in GFAP-cre:TrkBflox/flox mice $(n=13)$ compared with TrkBflox/flox control littermates $(n=20)$. P-value lines refer to significant differences over time. Error bars indicate SEM. (F) Table summarizing EAE clinical parameters in GFAP-cre:TrkBflox/flox mice and control littermates. Data from three EAE experiments were pooled, analyzed, and given as mean \pm SEM. Only diseased animals were included in the analysis for the onset, max score, score at peak, and cumulative disease index (C.D.I.). p.i., postimmunization. (G) Proliferation of draining lymph node (drLNs; top) or spleen (bottom) cells of GFAP-cre:TrkBflox/flox $(n=5)$ and TrkBflox/flox ( $n=5$ ) mice at day 10 after immunization with $\mathrm{MOG}_{35-55}$ peptide, as assessed by [ $\left.{ }^{3} \mathrm{H}\right]$ thymidine incorporation. Values are expressed as percentage of unstimulated control cells. Similar observations were obtained in a second experiment. Error bars indicate SEM. ${ }^{*}, P<0.05 ;{ }^{* *}, P<0.01 i^{* * *}, P<0.001$. 

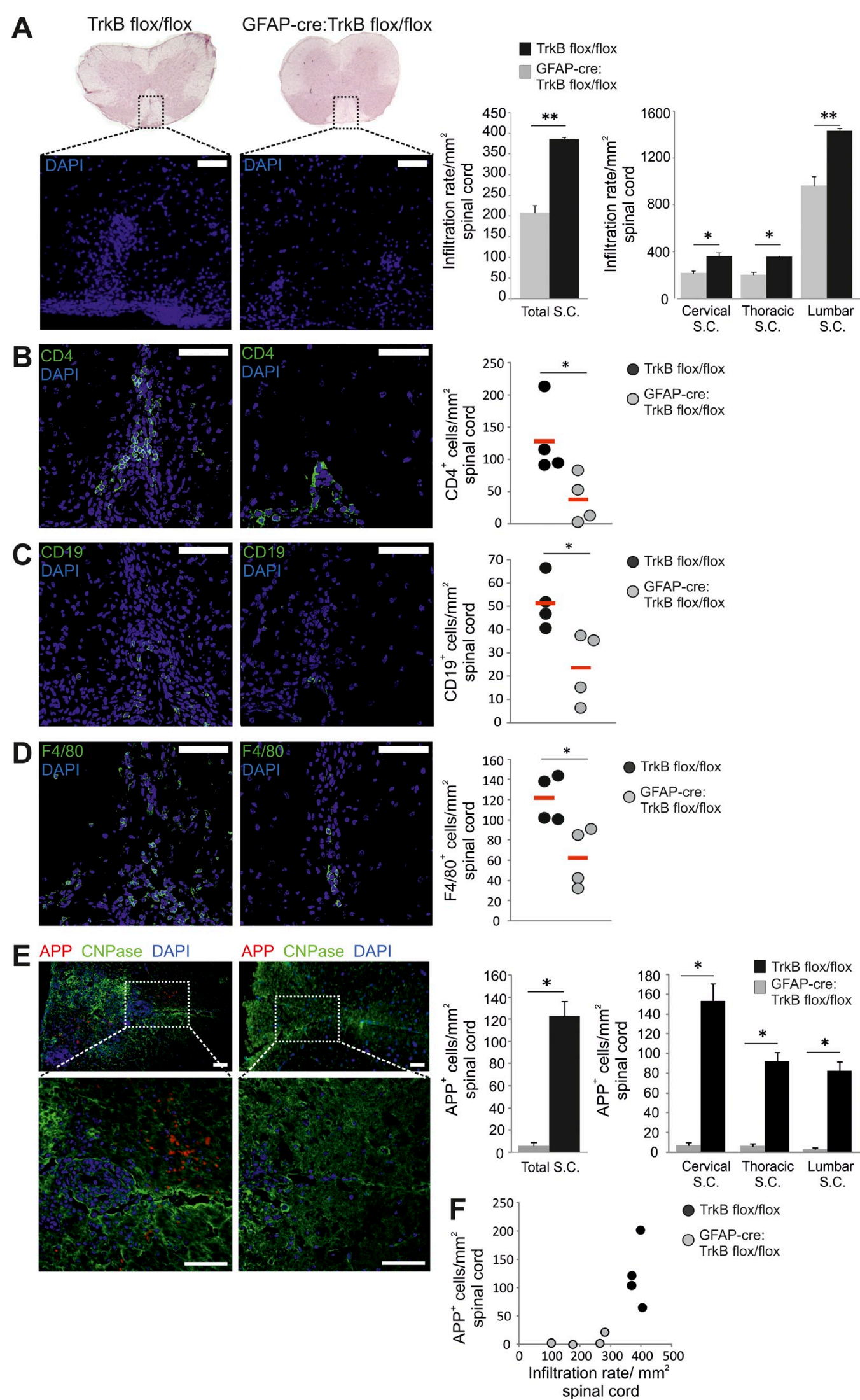

Figure 3. GFAP-cre:TrkBflox/flox mice are protected from EAE-associated neurodegeneration. (A-D) Inflammation at peak of disease. (A) Images show hematoxylin and DAPI stainings of the spinal cord (S.C.) of GFAP-cre:TrkBflox/flox (right) and TrkBflox/flox mice (left) at day 18 after 


\section{Human astrocytes up-regulate the TrkB receptor in MS lesions}

We used immunohistochemistry with an antibody directed against the TrkB extracellular domain (ECD) on 14 normal control brain white matter samples and 12 chronic inactive MS lesions. Although localized on occasional cells with astrocytelike morphology in normal control brain (Fig. 4 A, first panel), the neurotrophin receptor was strongly expressed in MS lesions (Fig. 4 B, first panel). Confocal microscopy showed that TrkB labeled a few GFAP-positive astrocytes in control white matter (Fig. 4 A, second panel). Similarly to the inflamed white matter of $\mathrm{MOG}_{35-55}$ immunized mice, in MS lesions, TrkB was expressed on the network of astrocytic processes (Fig. 4 B, second panel).

In addition to the human full-length TrkB, two intracellularly truncated isoforms, TrkB-T1 and TrkB-Shc, have been described previously (Stoilov et al., 2002). We examined their transcript levels by quantitative PCR on human brain cDNA samples. TrkB-T1 was the most abundant isoform in controls and was significantly up-regulated in MS lesions, whereas TrkB-TK and TrkB-Shc were barely detectable (Fig. 4 C). MS tissue samples were stained with antibodies specific for either the full-length (TrkB-TK) receptor or the truncated TrkB-T1 isoform. Although full-length TrkB was localized exclusively on some axons in both normal control tissues and MS lesions (Fig. 4, A and B, fourth panels), TrkB-T1 was present on astrocytes in control brain tissue (Fig. $4 \mathrm{~A}$, third panel) and strongly up-regulated on these cells in MS lesions (Fig. 4 B, third panel). In contrast, the p75NTR neurotrophin receptor was undetectable on astrocytes both in control and MS brain samples (Fig. 4, A and B, fifth panels). This observation was confirmed by immunofluorescence experiments with three distinct anti-p75NTR monoclonal antibodies (see Materials and methods) and is in agreement with other published data on human CNS specimens (Dowling et al., 1999; Holley et al., 2003; Petratos et al., 2004). In parallel to our in vivo observations, quantitative PCR experiments showed that truncated TrkB-T1 levels in cultured human astrocytes far exceeded those of the two other isoforms (Fig. 4 D). Flow cytometry for TrkB-ECD confirmed surface expression of the receptor on the majority of cultured astrocytes (Fig. 4 E), which were also positive for TrkB-T1 (Fig. 4 F) but not TrkB-TK (not depicted). Thus, human astrocytes preferentially express the truncated isoform of the neurotrophin receptor, which is up-regulated in MS lesions.

\section{BDNF-activated astrocytes induce fast neuronal degeneration}

To study the effects of TrkB ligation on glia-neuronal interactions, we developed an in vitro model system with human primary fetal astrocytes and rat primary neurons. Astrocytes were treated for $4 \mathrm{~h}$ with BDNF or the inflammatory stimulus IL1. Medium was then changed to remove recombinant factors, and supernatants were collected after a further $24 \mathrm{~h}$ in culture. This astrocyte-conditioned medium (ACM) was then incubated with the neurons.

First, we performed live imaging of cultures exposed to ACM for $20 \mathrm{~h}$. Neurons showed no morphological changes when exposed to supernatants from nontreated astrocytes (sNT; Fig. 5 A, Fig. S1, and Video 1). Conversely, supernatants from IL1-treated astrocytes (sIL1) triggered a rapid degenerative response in neurons (Fig. 5 A, Fig. S1, and Video 2). These cultures showed budding of vesicles, fragmentation, retraction, and thinning of extensions, similarly to what has been described in vivo during degeneration (Kerschensteiner et al., 2005; Trapp and Stys, 2009). Within a few hours, neuronal processes were disrupted, and rounded-up cell bodies showed signs of nuclear condensation. Surprisingly, a very similar phenomenon was observed when neurons were exposed to supernatants from BDNF-treated astrocytes (sBDNF; Fig. 5 A, Fig. S1, and Video 3). Imaging of neuronal cultures exposed to recombinant BDNF did not show significant neurodegeneration until 20-h incubation (rBDNF; Fig. 5 A and Video 4). Overall, these observations indicate that astrocytic responses to BDNF may accelerate neurodegenerative processes.

As live-imaging fields contained limited numbers of cells, we further quantified this phenomenon in larger areas of neuronal cultures. Instead of phase-contrast images, $\beta$-tubulin staining was used to better define neuronal bodies and processes (Melli et al., 2006b). A clear drop in $\beta$-tubulin mean fluorescence intensity (MFI) was observed in sBDNF cultures (Fig. 5, B and C), which was significant at low BDNF concentrations $(1-5 \mathrm{ng} / \mathrm{ml})$ and comparable with sIL1 cultures (Fig. 5 C, first panel). Conversely, the same amount of BDNF was unable to trigger degeneration when given directly to neurons (rBDNF; Fig. 5 D, first panel). Both the percentage of cells with neurites and neurite length decreased to similar extents in neuronal cultures incubated with sIL1 or sBDNF (Fig. $5 \mathrm{C}$, second and third panels), whereas rBDNF induced only minor effects at $25 \mathrm{ng} / \mathrm{ml}$ (Fig. 5 D). Finally,

immunization with $\mathrm{MOG}_{35-55}$ peptide. Graphic plots show quantification of white matter inflammation in different regions of the spinal cord in GFAP-cre: TrkBflox/flox mice and control littermates. The infiltration rate in the ventral white matter of the mouse spinal cord was calculated as the ratio in the number of DAPI+ nuclei between EAE mice and naive mice per unit of area. (B-D) Immunofluorescence for CD4, CD19, or F4/80 in GFAP-cre:TrkBflox/flox (right) and control mouse (left) spinal cord. Graphic plots show relative quantification. Red lines represent mean values for each group. Each dot represents an individual mouse. (E) Neurodegeneration at peak of disease. Confocal images show APP deposition in spinal cord white matter in GFAP-cre: TrkBflox/flox mice (right) and TrkBflox/flox control littermates (left), evaluated at day 18 after immunization. Relative quantification is given in the graphs. (A and E) Error bars indicate SEM. (F) Neurodegeneration versus infiltration rate in GFAP-cre:TrkBflox/flox mice and TrkBflox/flox control littermates. Four mice/group from two independent EAE experiments were analyzed. Bars, $50 \mu \mathrm{m}$. One z-stack images. ${ }^{*}, \mathrm{P}<0.05 ;{ }^{* *}, \mathrm{P}<0.01$. 
both sBDNF and sIL1 supernatants induced massive apoptosis as detected by TUNEL (Tdt-mediated dUTP-biotin nick end labeling) staining (Fig. $5 \mathrm{C}$ ). Apoptosis was also triggered directly by the recombinant factors (Fig. 5 D), although less efficiently than by supernatants from activated astrocytes. Thus, both IL1 and BDNF induced neurodegeneration and apoptosis directly, but astrocytic activation via the same factors strongly amplified these pathogenic processes through fastacting soluble factors. Interestingly, similarly to BDNF, the neurotrophins NT3 and NT4 could also activate the astrocytes and induce neurodegeneration and apoptosis (Fig. 5 E).

Responses to neurotrophins may be mediated by the Trk receptors and/or by the neurotrophin receptor p75NTR (Huang and Reichardt, 2003). Flow cytometry showed low p75NTR expression on a small fraction of cultured astrocytes (Fig. $5 \mathrm{~F}$ ), raising the possibility that the in vitro observations were dependent on p75NTR rather than TrkB signaling. To clarify this issue, first of all, we performed blocking experiments with a specific anti-p75NTR antibody (Wong et al., 2002; Colombo et al., 2011b). As shown in Fig. $5 \mathrm{G}$, astrocyte stimulation with BDNF in the presence of the blocking anti-p75NTR antibody induced disruption of the neuronal network and apoptosis to the same extent as control cultures. Second, we isolated and cultured astrocytes from GFAP-cre:TrkBflox/flox and control TrkBflox/flox mice. As expected, TrkB transcript was expressed in wild-type $(2.4 \pm$ $0.73 \%$ of the housekeeping gene GAPDH) but not $\mathrm{KO}$ astrocytes $(0 \%)$. Immunofluorescence confirmed TrkB protein depletion in astrocytes (Fig. 6 A). Furthermore, both cultures did not show p75NTR expression ( $0 \%$ of the housekeeping gene). Similarly to the experiments with human astrocytes, exposure of mouse wild-type astrocytes to BDNF and IL1 led to the release of soluble factors, which induced $\beta$-tubulin loss and apoptosis (Fig. $6 \mathrm{~B}$, black bars). Importantly, $\mathrm{KO}$
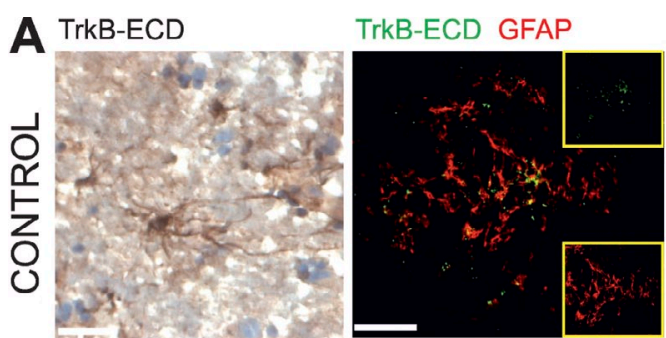

TrkB-T1
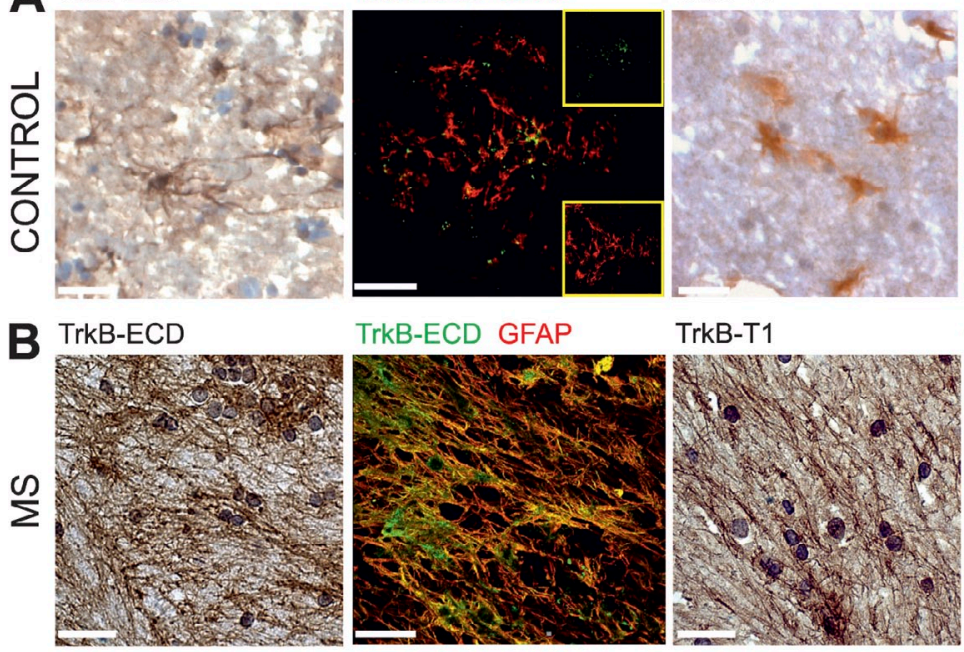

TrkB-ECD GFAP

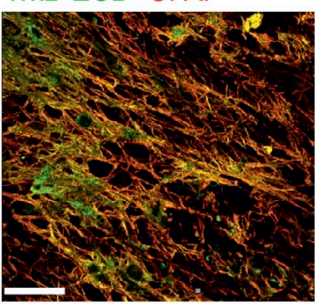

TrkB-T1

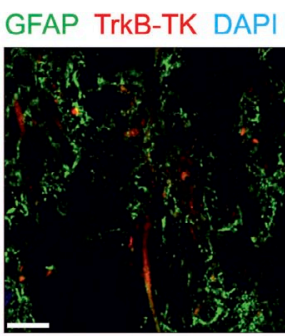

GFAP TrkB-TK DAPI

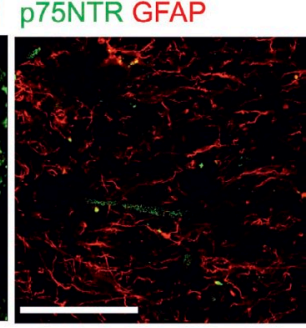

p75NTR GFAP

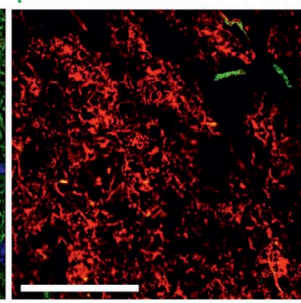

$\mathbf{F}$

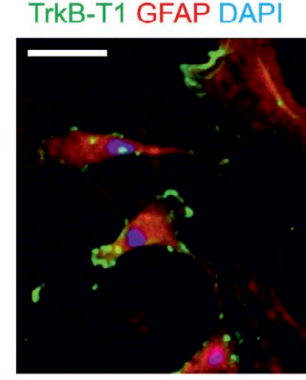

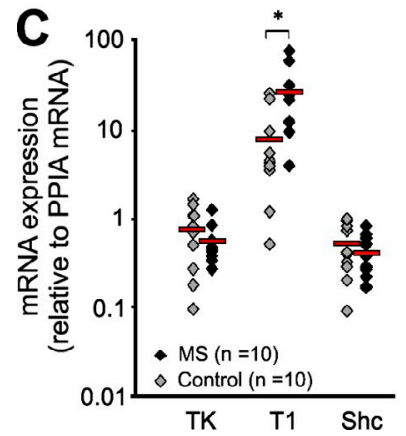
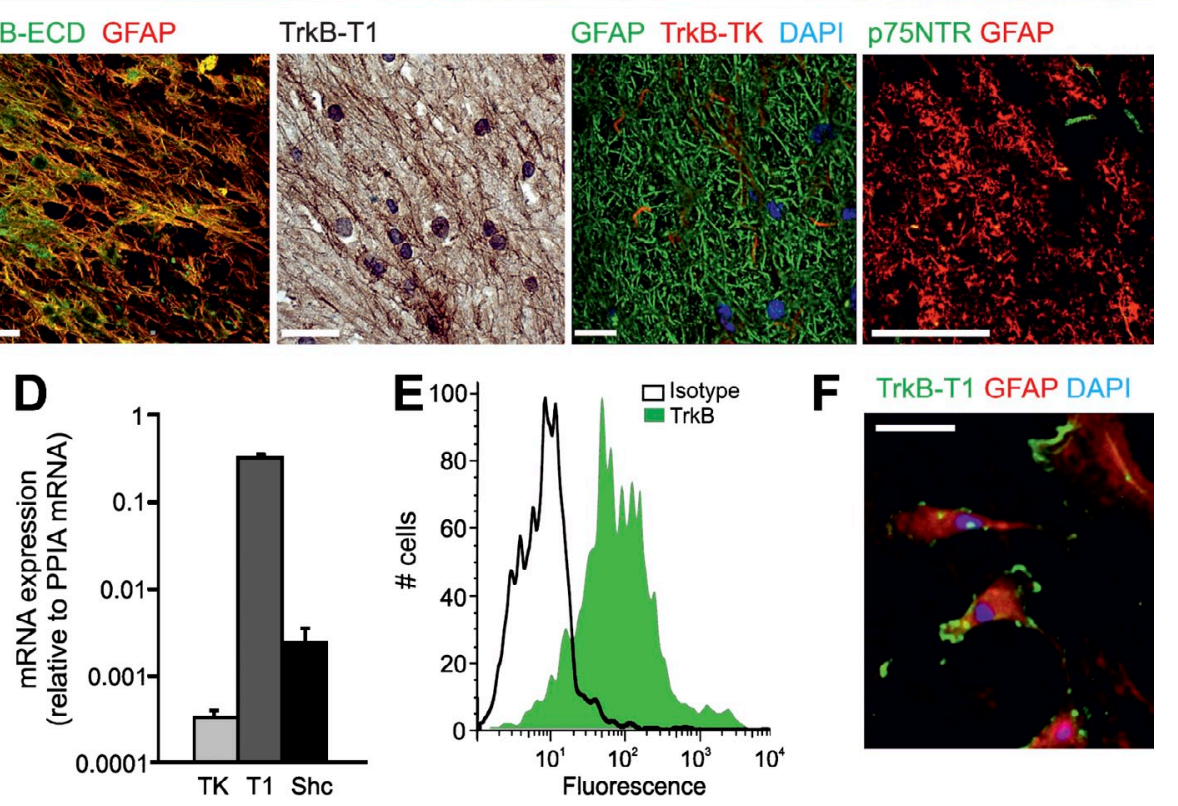

Figure 4. TrkB is expressed by human astrocytes in vivo and in vitro and up-regulated in MS lesions. ( $A$ and $B$ ) TrkB and p75NTR protein expression in normal control white matter (A) or MS chronic inactive lesions (B). Left panels show immunostainings with an antibody directed to the TrkB-ECD. In the first column, immunohistochemistry demonstrates brown DAB staining on astrocyte-like cells. Double immunofluorescence and confocal imaging for TrkB-ECD and GFAP are shown in the second column. Insets depict single stainings. Third and fourth columns show immunostainings for TrkB isoforms: TrkB-T1 isoform (brown DAB staining) in the third column and full-length TrkB (TrkB-TK) in the fourth column. The fifth column shows the absence of p75NTR immunoreactivity in GFAP-positive astrocytes. Representative stainings are shown. DAPI was used to stain for nuclei. (C and D) Quantitative PCR assessment of messenger RNA (mRNA) transcripts encoding full-length TrkB-TK and the truncated T1 or Shc isoforms in normal control white matter (control) and MS lesions (MS; C) and in human primary astrocytes (D). Data are expressed as the percentage of the housekeeping gene PPIA. Red lines represent mean values for each group. Error bars indicate SD. ${ }^{*}, P<0.05$. (E) Cytofluorimetric analysis of TrkB surface expression in human cultured astrocytes. (F) Confocal microscopy for TrkB-T1 isoform, GFAP, and DAPI in cultured astrocytes. Bars, $50 \mu \mathrm{m}$. 

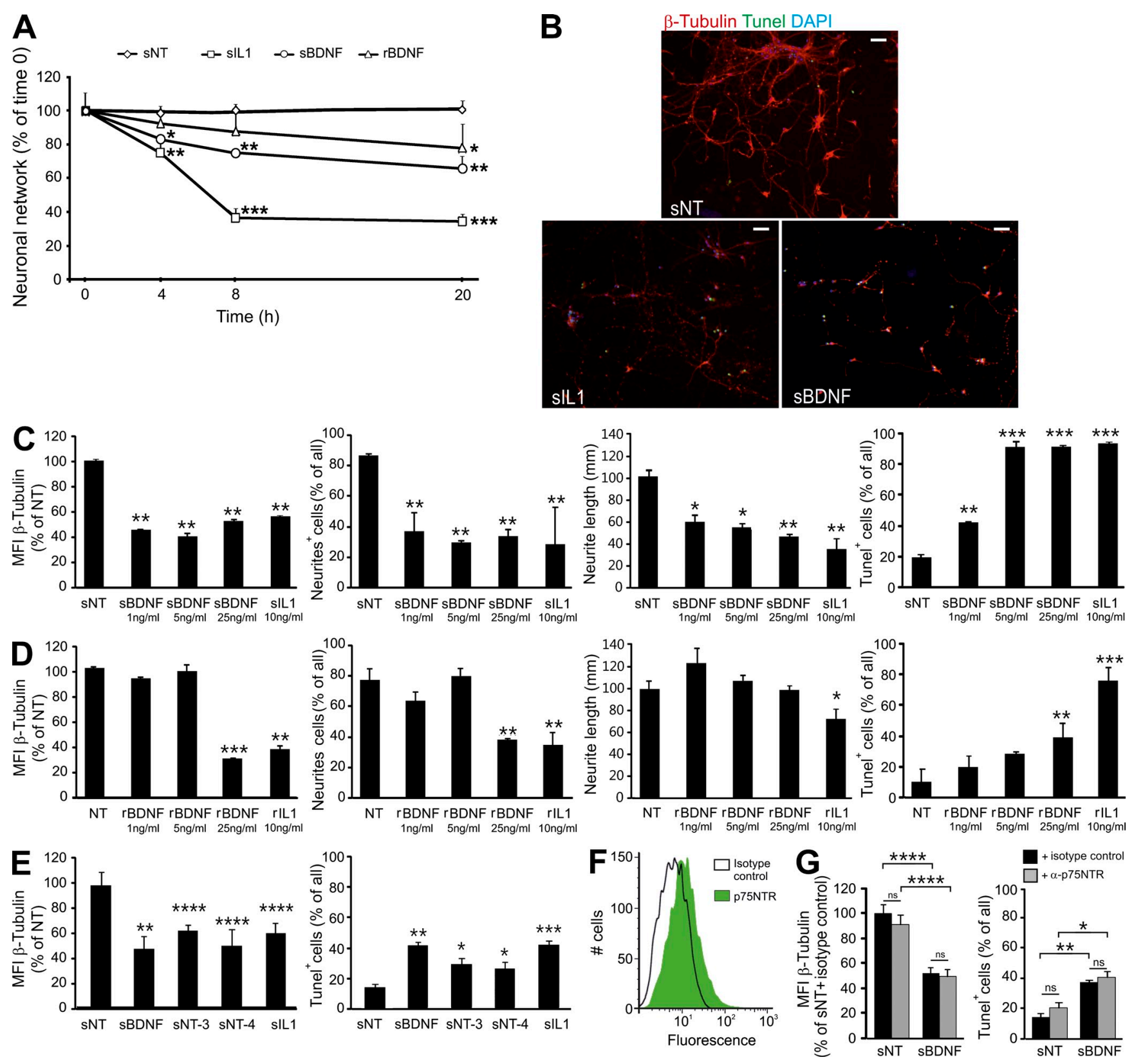

Figure 5. Astrocyte responses to neurotrophins induce neurite fragmentation and neuronal death and do not require p75NTR. (A) Kinetics of changes in neuronal morphology after exposure to ACM as monitored by live imaging. Stimuli (IL1 or BDNF) or vehicle was given to astrocytes for $4 \mathrm{~h}$ and then removed. Cells received fresh medium and were cultured for a further $24 \mathrm{~h}$. Then the ACM was collected and added to cultured neurons. Neurons were incubated with supernatants from nontreated (sNT), IL1-treated (10 ng/ml; sIL1), or BDNF-treated astrocytes (5 ng/ml; sBDNF) or to direct recombinant BDNF ( $5 \mathrm{ng} / \mathrm{ml}$; rBDNF). Neuronal network was calculated as color density in the image field, and changes over time were visualized as the percentage of time point 0 . Five videos were analyzed per treatment at four time points. (B) Fluorescence images showing representative stainings for $\beta$-tubulin, DAPI, and TUNEL in neuronal cultures after 24-h exposure to ACM. Bars, $50 \mu \mathrm{m}$. (C) Quantification of $\beta$-tubulin MFI, number of cells with neurites, length of neurites, and percentage of apoptotic cells in neuronal cultures exposed to ACM. Changes in $\beta$-tubulin MFI were calculated as the percentage of MFI in control cultures exposed to ACM from nontreated (SNT) astrocytes. Data were obtained in at least three independent experiments. (D) The same parameters as in $\mathrm{C}$ in neuronal cultures treated with recombinant BDNF (rBDNF) or IL1 (rIL1). Data were obtained in three independent experiments. (E) Astrocytes were treated with $5 \mathrm{ng} / \mathrm{ml}$ BDNF, NT-3, NT-4, or $10 \mathrm{ng} / \mathrm{ml} \mathrm{IL1}$. Neuronal cultures were exposed to ACM, and $\beta$-tubulin MFI and the percentage of apoptotic cells were evaluated. Data were obtained in three independent experiments. (F) Cytofluorimetric analysis of p75NTR surface expression on human cultured astrocytes. (G) $25 \mathrm{ng} / \mathrm{ml}$ BDNF or vehicle was given to astrocytes for $4 \mathrm{~h}$ in the presence of p75NTR blocking antibody or isotype control and then removed. Cells received fresh medium and were cultured for a further $24 \mathrm{~h}$. Then the ACM was collected and added to cultured neurons. Graphs show quantification of $\beta$-tubulin MFI and the percentage of apoptotic cells. Three independent experiments were performed. All data are represented as mean \pm SEM. ns, not significant. ${ }^{*}, \mathrm{P}<0.05^{* * *}, \mathrm{P}<0.01$; $^{* * *}, \mathrm{P}<0.001 ;{ }^{* * * *}, \mathrm{P}<0.0001$. 
astrocytes induced neurodegeneration in response to IL1 but not to BDNF (Fig. $6 \mathrm{~B}$, gray bars). We can conclude that astrocyte TrkB and not $\mathrm{p} 75 \mathrm{NTR}$ mediates responses to neurotrophins that trigger neurodegeneration.

\section{Neurodegeneration is initiated by NO synthesis and released by astrocytes in response to BDNF and sustained by secondary neuronal NO boosts}

As direct administration of recombinant BDNF at high doses induced neurodegeneration (Fig. 5 E), we wondered whether the effects mediated by the supernatants were caused by BDNF released by astrocytes. Neuronal cultures strongly expressed the p75NTR receptor but not TrkB (Fig. $7 \mathrm{~A}$ ), indicating that responses to neurotrophins in neurons and in astrocytes were depending in our system on distinct receptors. We measured human BDNF levels in astrocyte supernatants by ELISA; however, they were $<20 \mathrm{pg} / \mathrm{ml}$ at the ACM dilution given to the neuronal cultures (not depicted). We further checked the potential involvement of astrocyte-derived BDNF in neurodegeneration by blocking experiments with a specific anti-BDNF antibody. As expected, when given to astrocytes (Fig. 7 B, gray bars), the blocking antibody inhibited both network disruption and apoptosis induced by sBDNF but not sIL1. In contrast, administration of the blocking antibody to the neuronal cultures together with sBDNF did not hinder the neurodegenerative process (Fig. $7 \mathrm{C}$ ), as $\beta$-tubulin loss and apoptosis were comparable with control cultures. These experiments clearly demonstrate that astrocytic BDNF is not the mediator driving neurodegeneration.

As neuronal degeneration may be triggered by NO (Brown and Bal-Price, 2003; Pacher et al., 2007) and astrocytes may produce it, we investigated $\mathrm{NO}$ involvement in the in vitro model system. First, astrocytes were loaded with the fluorescent NO indicator DAF-FM, stimulated with BDNF, and observed over $4 \mathrm{~h}$ by live imaging. Although resting cells did not develop any fluorescence (Fig. $8 \mathrm{~A}$ and Video 5), BDNF- or IL1-treated astrocytes started producing $\mathrm{NO}$ during the first stimulation hour (Videos 6 and 7, respectively, and Fig. 8 A). Quantification of fixed samples after $1.5 \mathrm{~h}$ revealed that $50 \%$ of astrocytes produced $\mathrm{NO}$ upon treatment with $5 \mathrm{ng} / \mathrm{ml}$ BDNF (Fig. 8 B). NO formation was TrkB dependent, as astrocytes from GFAP-cre:TrkBflox/flox mice did not produce NO in response to BDNF (Fig. $8 \mathrm{C}$, gray bars), whereas wild-type astrocytes (Fig. $8 \mathrm{C}$, black bars) did it at levels similar to human astrocytes (Fig. 8 B). When an NO synthase inhibitor, L-nitroarginine methyl ester (L-NAME), was added to human cultures together with stimuli, astrocytes produced much less NO (Fig. 8 D). Second, we tested whether the stable NO breakdown products (nitrites and nitrates) were present in astrocyte supernatants and found that BDNF and IL1 could indeed induce NO release from astrocytes (Fig. 8 E). Third, to prove the neurotoxic role of astrocytic NO, we incubated neurons with ACM from cells treated with L-NAME and then examined $\beta$-tubulin expression and apoptosis. When generated in the presence of L-NAME, sBDNF supernatants caused no disruption of neuronal processes and limited cell apoptosis (Fig. 8, F and G). Fourth, we blocked NO production in neurons by L-NAME and exposed them to ACM. This treatment hampered neurodegeneration and reduced the percentage of apoptotic cells (Fig. 8, H and I), demonstrating that neuronal NO, although triggered by BDNF-induced astrocytic NO, amplifies the process. Fifth, nitrotyrosine-positive neurons were detected in sBDNF or sIL1 cultures (Fig. 9 A), clearly indicating the NO-dependent posttranslational nitrosylation of intracellular proteins.

Finally, we examined NO synthesis and nitrosylation in vivo. Experimental neuroinflammation is characterized by peroxynitrite production in the CNS (Cross et al., 1997). Consistently, TrkBflox/flox EAE mice displayed strong immunoreactivity for the inducible NO synthase (iNOS), and astrocytes greatly contributed to iNOS expression as
A

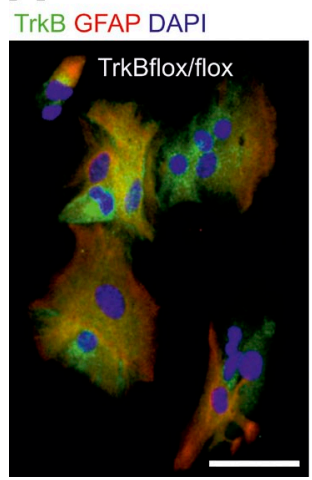

B - ACM TrkBlioxfliox

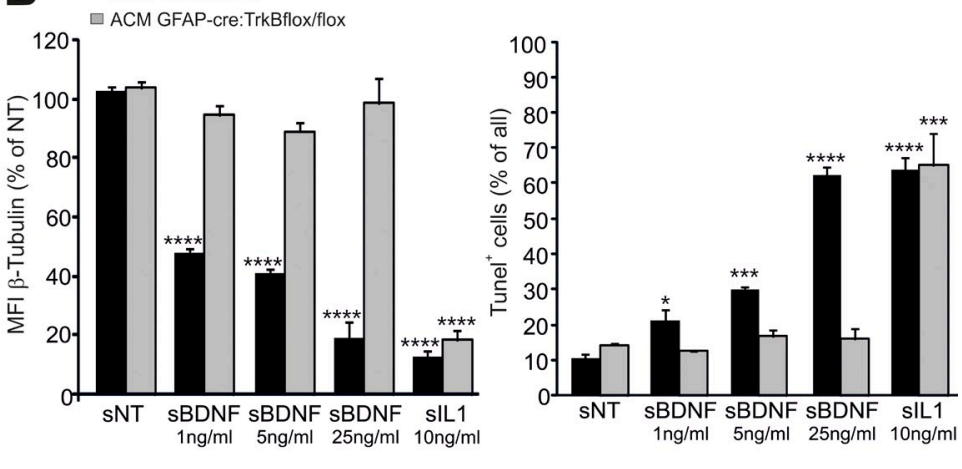

Figure 6. Neurodegeneration induced by astrocyte responses to BDNF depends on astrocyte TrkB. (A) Double immunofluorescence for TrkB and GFAP in mouse cultured astrocytes. DAPI was used to stain for nuclei. Bars, $20 \mu \mathrm{m}$. (B) Assay performed as in Fig. 5 on mouse astrocytes. Graphs show quantification of $\beta$-tubulin MFI and the percentage of apoptotic cells in neuronal cultures exposed to ACM from GFAP-cre:TrkBflox/flox and TrkBflox/flox astrocytes treated as indicated. Data were obtained in three independent experiments and are represented as mean \pm SEM. Statistics refer to comparisons with relative sNT (nontreated). ${ }^{*}, \mathrm{P}<0.05 ;{ }^{* * *}, \mathrm{P}<0.001 ;{ }^{* * * *}, \mathrm{P}<0.0001$. 
shown by the abundant iNOS signal in GFAP-positive cells (Fig. 9 B). In contrast, GFAP-cre:TrkBflox/flox EAE mice displayed a dramatic reduction in iNOS expression, which remained confined to some infiltrating immune cells (Fig. 9 B). Similarly, tyrosine nitrosylation was significantly impaired in GFAP-cre:TrkBflox/flox EAE mice but was strongly detected in control EAE mice (Fig. 9 C). Parallel analysis of human brain tissue samples showed that, although absent in normal control white matter (not depicted), nitrosylation was detected in MS lesions (Fig. 9 D). Interestingly, we observed nitrotyrosine-positive axons surrounded by and in contact with the TrkB-positive gliotic network (Fig. 9 D).

A
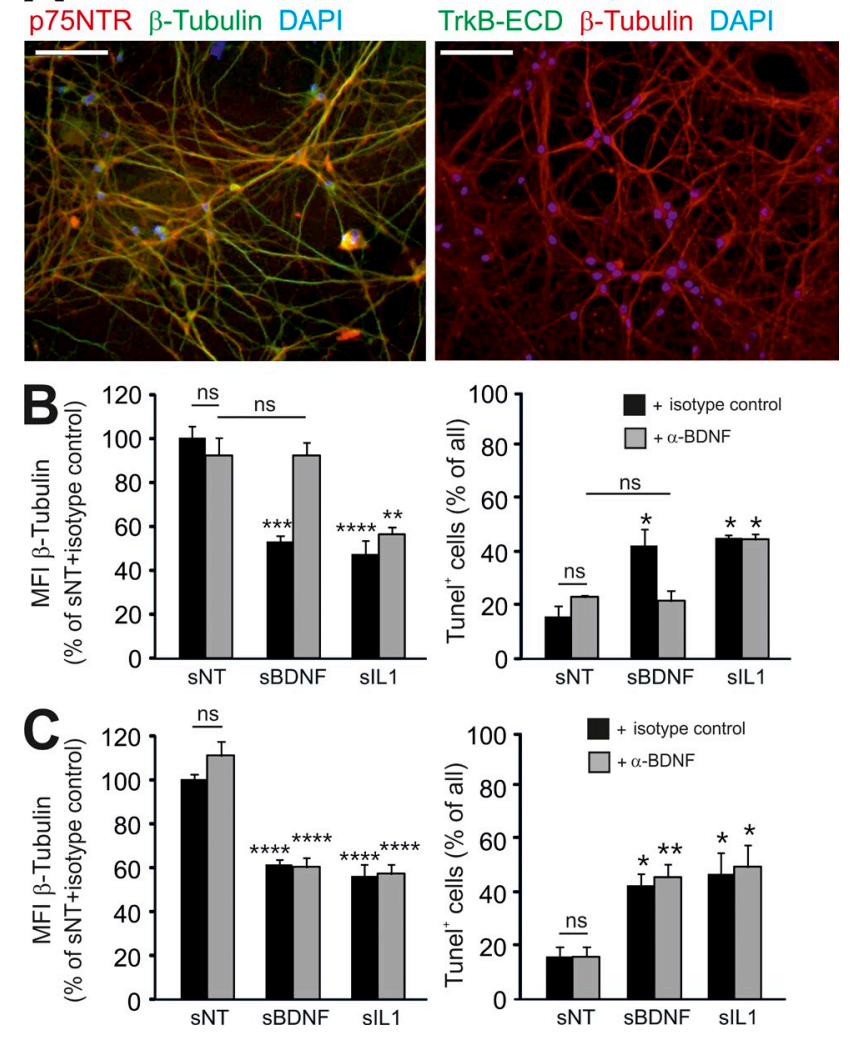

Figure 7. Astrocyte BDNF is not the mediator triggering neurodegeneration. (A) Double immunofluorescence for p75NTR or TrkB and $\beta$-tubulin in rat primary neurons. Bars, $50 \mu \mathrm{m}$. (B and $\mathrm{C}$ ) Assay performed as in Fig. 5, but BDNF-neutralizing or isotype antibody was added to astrocyte cultures (B) or to neuronal cultures exposed to BDNF (C). In B, stimuli ( $10 \mathrm{ng} / \mathrm{ml} \mathrm{IL1} \mathrm{or} 25 \mathrm{ng} / \mathrm{ml}$ BDNF) or vehicle was given to astrocytes in the presence of BDNF blocking antibody or isotype control for $4 \mathrm{~h}$ and then removed. After $24 \mathrm{~h}$, the ACM was collected and added to cultured neurons. In $\mathrm{C}$, astrocytes were treated with stimuli for $4 \mathrm{~h}$. After $24 \mathrm{~h}$, ACM was given to cultured neurons together with BDNF blocking antibody or isotype control. Graphs show quantification of $\beta$-tubulin MFI and the percentage of apoptotic cells. All data were obtained in at least two independent experiments and are represented as mean \pm SEM. If not indicated, statistics refer to comparisons with relative SNT (nontreated). ns, not significant. ${ }^{*}, \mathrm{P}<0.05 i^{* *}, \mathrm{P}<0.01 i^{* * *}, \mathrm{P}<0.001 i^{* * * *}, \mathrm{P}<0.0001$.

\section{DISCUSSION}

In this paper, we addressed the role of the neurotrophin receptor TrkB in white matter pathology. TrkB transcripts are up-regulated in normal-appearing MS white matter (Graumann et al., 2003) and in chronic MS lesions (Mycko et al., 2004); however, their cellular sources have not been identified. We observed robust expression of TrkB on astrocytes in both EAE and MS lesions. Similarly, TrkB is enhanced in astrocytes in injured white matter (Frisén et al., 1993; Widenfalk et al., 2001) and after neoplastic transformation (Wang et al., 1998), suggesting a link between astrocyte activation and TrkB up-regulation. We demonstrated in our quantitative PCR experiments on human cerebral tissue that there was marked up-regulation of the truncated isoform TrkB-T1 in MS tissue compared with control white matter, which was confirmed at the protein level by immunohistochemistry with a specific antibody directed to the noncatalytically active isoform. TrkB-T1 was up-regulated on astrocytes in EAE lesions as well. During mouse development, the expression of TrkB isoforms is tightly regulated in the CNS (Allendoerfer et al., 1994), and, interestingly, the shift from the full-length to the truncated isoform correlates with the onset of neuronal death and maturation of axonal connections (Allendoerfer et al., 1994; Ohira et al., 1999). A few studies demonstrate that dysregulation of TrkB isoforms in neurons may lead to cell death (Dorsey et al., 2002, 2006). In contrast, astrocytes express only truncated TrkB receptors (Rose et al., 2003; Ohira et al., 2005; Dorsey et al., 2006).

Although bearing a very short cytoplasmic domain, astrocyte TrkB mediates responses to BDNF, such as calcium release (Rose et al., 2003) and cytoskeletal rearrangements (Ohira et al., 2005). Initially we had decided to analyze the role of astrocyte TrkB in vivo in experimental neuroinflammation. Surprisingly, conditional mice lacking TrkB on GFAP-positive cells showed strong impairment in EAE susceptibility and severity. Histological analyses indicated that immune infiltrates were present in the spinal cord white matter of the EAE KO mice, although significantly less than in control EAE littermates. Moreover, neurodegeneration was almost absent in $\mathrm{KO}$ mice. Overall, our observations indicating that the TrkB-dependent astrocytosis supports neuroinflammation and, more strongly, neurodegeneration are in contrast with the well-established neurotrophic functions of TrkB ligands. For example, BDNF has a pivotal role in the development of the fetal and postnatal brain, and conventional BDNF KO mice die at birth (Korte et al., 1995). BDNF is also critical for the neurogenesis and the synaptic plasticity (Binder and Scharfman, 2004) as well as for the regeneration of neurons and axons after injury (Huang and Reichardt, 2003). BDNF is produced by resident CNS cells, but under inflammatory settings such as in MS, it may be also released by infiltrating immune cells (Stadelmann et al., 2002). Interestingly, BDNF production by peripheral immune cells of MS patients is enhanced upon immunomodulatory therapy (Azoulay et al., 2005, 2008, 2009; Sarchielli et al., 2007). Endogenous and immune cellderived BDNF can regulate experimental neuroinflammation. 
Transgenic mice with BDNF depletion in either astrocytes or immune cells show enhanced disease severity associated with axonal loss (Linker et al., 2010), suggesting a BDNF-mediated neuroprotective mechanism. However, neurotrophins have a Janus-like nature as they may also induce neuronal death in vitro (Friedman, 2000), and heterozygous $\mathrm{BDNF}^{-/+}$mice, which display half-normal BDNF levels, show ameliorated EAE (Javeri et al., 2010). These observations in BDNF transgenic animals suggest that alterations in the availability of BDNF may influence experimental neuroinflammation; however, they do not allow the dissection of the responses of distinct cell types to the neurotrophin. Moreover, our in vitro data show that, similarly to BDNF, the TrkB ligands NT3 and NT4 also activated the astrocytes so that neurodegeneration was induced, indicating multiple options for TrkB activation in astrocytes.
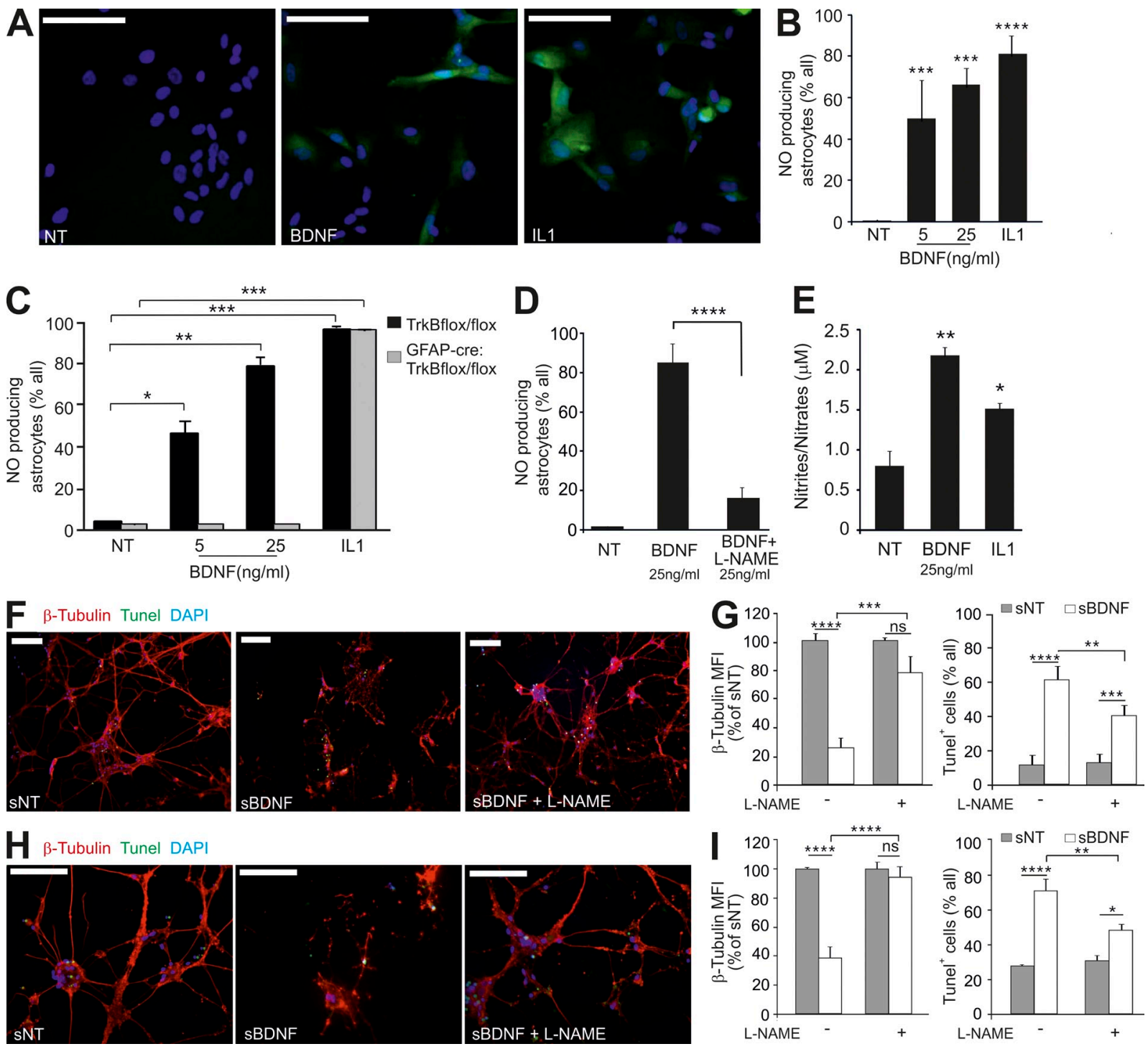

Figure 8. TrkB-dependent NO production by astrocytes in response to BDNF triggers neurodegeneration in vitro. (A) Human primary astrocytes loaded with NO dye DAF-FM were stimulated with $5 \mathrm{ng} / \mathrm{ml} \mathrm{BDNF}$ or $10 \mathrm{ng} / \mathrm{ml} \mathrm{IL1}$ or left nontreated (NT). NO-positive cells (green) were counted. Representative fields are shown. (B) Quantification of experiments described in A. The number of NO-producing cells is expressed as percent of total $\mathrm{DAPI}^{+}$cells. (C) Quantification as in B of NO production by nontreated or BDNF-treated astrocytes of TrkBflox/flox and GFAP-cre:TrkBflox/flox mice. (D) NO production in human astrocytes was evaluated as in A and B with the addition of the NO synthase inhibitor L-NAME, where indicated. (E) Analysis of total nitrite/nitrate concentration in human astrocyte supernatants after $24 \mathrm{~h}$ of the indicated treatment. (F-I) Assay was performed as in Fig. 5. L-NAME was added to astrocytes ( $F$ and $G$ ) or neurons ( $H$ and I). Representative stainings for $\beta$-tubulin, DAPI, and TUNEL in neuronal cultures ( $\mathrm{F}$ and $\mathrm{H}$ ) and quantification of $\beta$-tubulin MFI and apoptosis ( $\mathrm{G}$ and $\mathrm{I})$. Changes in $\beta$-tubulin MFI were calculated as the percentage of MFI in control cultures exposed to ACM from nontreated (SNT) astrocytes. A concentration of $25 \mathrm{ng} / \mathrm{ml}$ BDNF was used in F-I to induce maximal astrocyte activation. Data are shown as mean \pm SEM of three $(B, C, G$, and $I)$ or two ( $D$ and $E)$ independent experiments. Bars, $50 \mu m$. ns, not significant. ${ }^{*}, \mathrm{P}<0.05 i^{* *}, \mathrm{P}<0.01 ;{ }^{* * *}, \mathrm{P}<0.001 ;{ }^{* * *}, \mathrm{P}<0.0001$. 
A $\beta$-Tubulin Nitrotyrosine DAPI
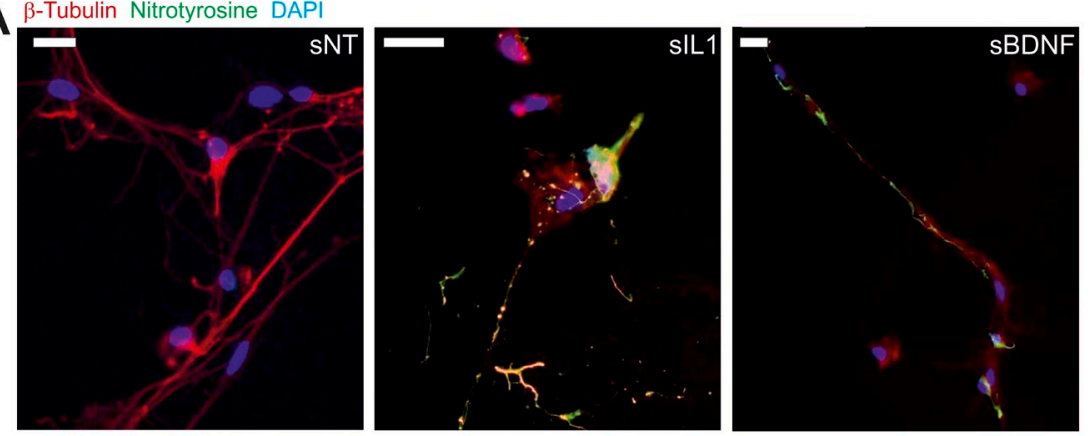

B

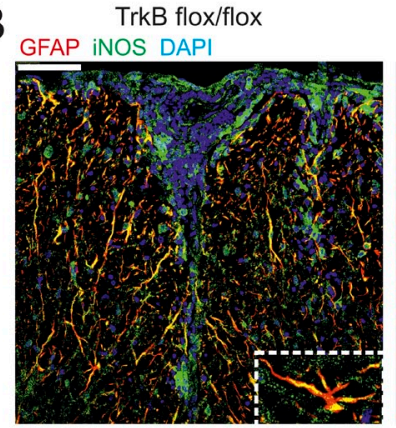

GFAP-cre:TrkB flox/flox

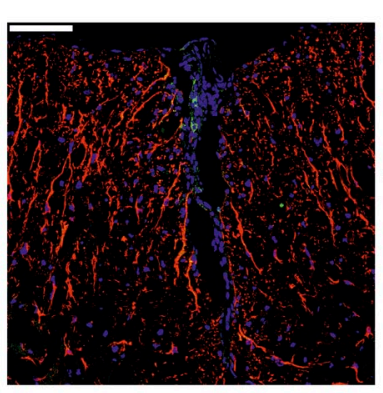

$\mathbf{C}_{\text {GFAP Nitrotyrosine DAPI }}^{\text {TrkB flox/flox }}$

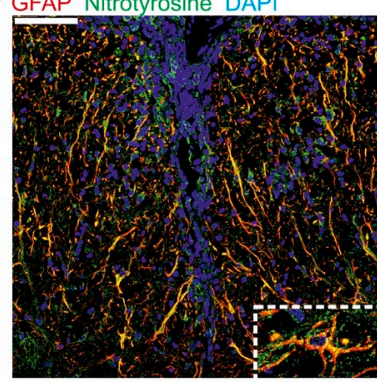

GFAP-cre:TrkB flox/flox
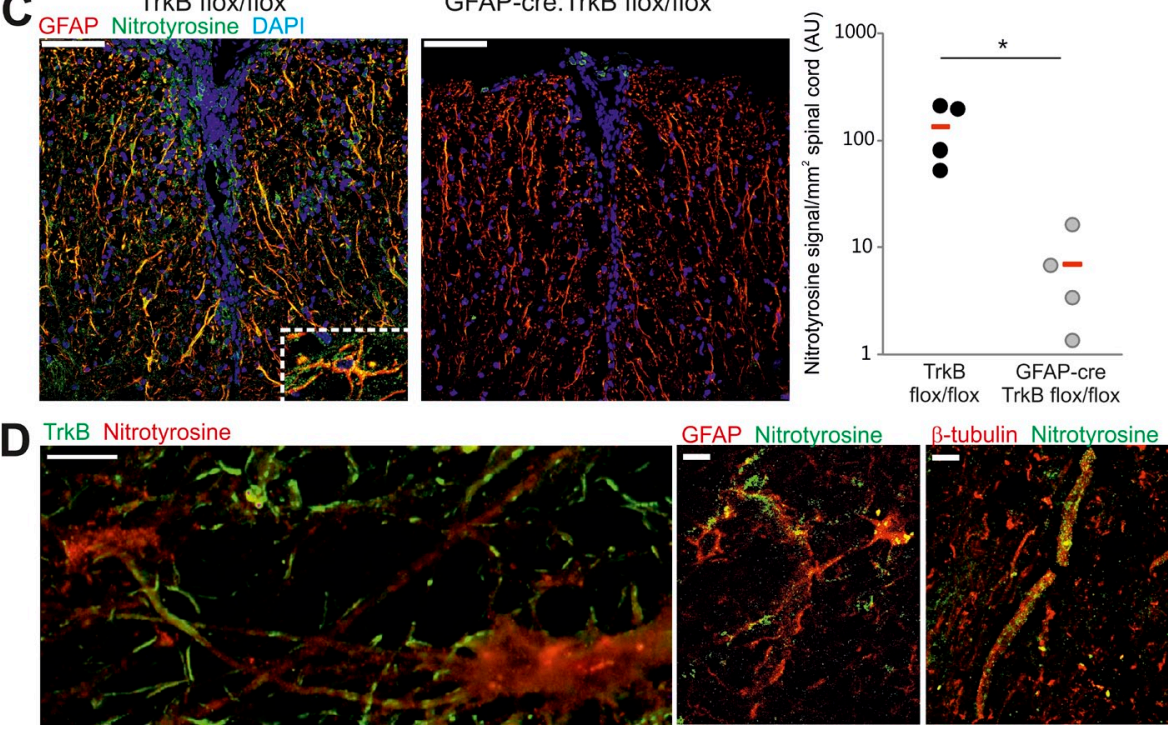

Figure 9. Tyrosine nitrosylation is detectable in vitro and in vivo and strongly reduced in GFAP-cre:TrkBflox/flox EAE mice. (A) Stainings for nitrotyrosine, $\beta$-tubulin, and DAPI in neuronal cultures exposed to ACM from nontreated (NT; left) and BDNF (middle)- or IL1-treated (right) astrocytes. (B and $C$ ) iNOS and nitrotyrosine expression in EAE mice. Double immunofluorescence for GFAP and iNOS (B) or nitrotyrosine (C) in spinal cord of TrkBflox/flox and GFAP-cre: TrkBflox/flox mice at day 18 after immunization with $\mathrm{MOG}_{35-55}$ peptide. Insets show enlarged images of iNOS- or nitrotyrosine-positive astrocytes. Graphs show relative quantification. Four mice/group from two independent EAE experiments were analyzed. Red lines indicate mean values for each group. ${ }^{*}, \mathrm{P}<$ 0.05. (D) Protein nitrotyrosilation in MS lesions. (left) Double immunofluorescence and confocal microscopy for TrkB-ECD and nitrotyrosine. (right) Nitrotyrosine localization on GFAP- or $\beta$-tubulin-positive cells. Representative images of three analyzed MS lesions; one z-stack images. Bars: (A and D) $10 \mu \mathrm{m}$; (B and C) $50 \mu \mathrm{m}$.

and apoptosis took place under both conditions, and NO was the common mediator released by astrocytes in response to both BDNF and IL1. These effects were dependent on astrocyte TrkB, as astrocytes from GFAP-cre: TrkBflox/flox mice did not produce $\mathrm{NO}$ and induce neuronal death. Furthermore, we demonstrated that the fast kinetics of the neurodegenerative phenomenon, highlighted by the timelapse imaging experiments, was driven by the release of astrocyte $\mathrm{NO}$ and amplified by neuronal NO. NO plays homeostatic, physiological functions in the CNS, including modulation of neurotransmission, neuroinflammation,

Astrocytes are important regulators of neuroinflammation and neurodegeneration. Published data show that NF- $\mathrm{B}$ signaling in astrocytes promotes neurotoxicity and CNS inflammation (Brambilla et al., 2009a,b; Dvoriantchikova et al., 2009; Fu et al., 2010). In this study, we describe for the first time that, as in a typical inflammatory pathway, the astrocytic response toward neurotrophins supports EAE expression by fostering a permissive environment for immune cell infiltration and neurodegeneration.

To study astrocyte-neuron interaction, we developed an in vitro model in which spinal neurons were exposed to ACM generated under BDNF stimulation and compared them with media generated under IL1 stimulation, which leads to $N F-\kappa B$ activation. Disruption of the neuronal network and neuroprotection (Calabrese et al., 2007). Basal NO levels are generated by nNOS and eNOS, which are $\mathrm{Ca}^{2+/}$ Calmodulin-dependent isoforms of NO synthases expressed by neurons, astrocytes, and endothelial cells (Calabrese et al., 2007). Nitrosative stress has been well documented in several neurodegenerative disorders. Here, NO is produced in excess after activation of iNOS. Importantly, iNOS up-regulation takes place in astrocytes in MS (Liu et al., 2001; Jack et al., 2007) and EAE (Cross et al., 1997) lesions. A marker of nitrosative stress is the nitrosylation of proteins at the level of tyrosine residues. We confirmed iNOS up-regulation and deposition of nitrotyrosine in vivo in the spinal cord of control EAE mice. Consistent with the in vitro data obtained from TrkB-deficient astrocytes (Fig. $8 \mathrm{C}$ ), both iNOS and 
nitrotyrosine signals were greatly reduced in the CNS of GFAP-cre:TrkBflox/flox EAE mice, indicating that TrkB signaling in astrocytes is crucial for NO synthesis in vivo. Thus, the decreased immune cell infiltration and neurodegeneration in the double transgenic EAE animals could be linked to the reduced NO production, considering that NO is a positive regulator of vascular permeability and forms neurotoxic products. Interestingly, in MS lesions, areas with diffuse nitrosylation were detected, and nitrosylated axons were surrounded by the TrkB-positive glial network.

In summary, our data indicate that the in vitro TrkBdependent astrocyte response to neurotrophins may cause neurodegeneration via NO release and that the abolition of this pathway in vivo confers resistance to neurodegeneration induced by experimental neuroinflammation. NO triggers neuronal death by altering energy metabolism (Brorson et al., 1999), and mitochondrial dysfunction has been reported in MS lesions (Mahad et al., 2008). Thus, it may be speculated that in MS, the up-regulated expression of TrkB on astrocytes contributes to the neuronal damage via NO production. Strategies to blockade this neurodegenerative pathway could lead to the development of a novel neuroprotective therapy for MS.

\section{MATERIALS AND METHODS}

Mice. Mice carrying loxP-flanked TrkB alleles (Luikart et al., 2005) were provided on a mixed background by L.F. Parada. Mice were backcrossed with wild-type C57BL/6N mice for seven generations before crossing with C57BL/6N hGFAP-cre transgenic mice (NCI-MMHCC) to obtain GFAPcre:TrkBflox/flox conditional mutant mice and control TrkBflox/flox littermates. As reported, the GFAP-cre transgene mediates excision of LoxP-flanked sequences in GFAP-expressing cell lineages (Malatesta et al., 2003; Cai et al., 2007), and transgenesis in the hGFAP promoter has been extensively used to assess functions of spinal cord astrocytes in adult animals (Brambilla et al., 2005, 2009b). Because loxP sites flank both transcription initiation sites and the first coding exon of the TrkB gene, all TrkB isoforms are deleted. The GFAP-cre:TrkBflox/flox conditional mutant mice are viable and live to adulthood (Luikart et al., 2005).

EAE induction. EAE was induced in 8-wk-old female mice by subcutaneous injection of $200 \mu \mathrm{g} \mathrm{MOG}_{35-55}$ emulsified in complete Freund's adjuvant containing $5 \mathrm{mg} / \mathrm{ml}$ Mycobacterium tuberculosis (DIFCO). Bordetella pertussis toxin (List-Quadratech) was administered by intraperitoneal injection on the day of immunization ( $400 \mathrm{ng} /$ mouse) and $2 \mathrm{~d}$ later $(200 \mathrm{ng} / \mathrm{mouse})$. Animals were monitored daily by measuring weight and examining disease scores as follows: $0=$ no disease, $1=$ flaccid tail, $2=$ gait disturbance, $3=$ complete hind limb paralysis, $4=$ tetraparesis, and $5=$ death. One experimenter was blind to mice genotypes. All procedures involving animals were authorized by the Italian General Direction for Animal Health at the Ministry for Health.

Primary immune responses. Cells from spleens and draining lymph nodes (popliteal, inguinal, paraaortal, and axillar) of GFAP-cre:TrkBflox/flox and TrkBflox/flox mice were harvested at day 10 after immunization with $\mathrm{MOG}_{35-55}$ peptide. $2 \times 10^{5}$ cells/well were seeded in 96-well round-bottom plates in RPMI + 5\% FCS and stimulated with increasing concentrations of $\mathrm{MOG}_{35-55}$ peptide. After $72 \mathrm{~h}$ of incubation $\left(37^{\circ} \mathrm{C}, 5 \% \mathrm{CO}_{2}\right)$, cultures were pulsed for $18 \mathrm{~h}$ with $0.5 \mu \mathrm{Ci} /$ well of $\left[{ }^{3} \mathrm{H}\right]$ thymidine, and proliferation was measured from quintuplicate cultures on a $\beta$ counter (PerkinElmer).

Human MS and control tissue samples. 12 brain samples from six female MS patients (aged 43-71 yr) and 14 from six female healthy controls (aged 37-79 yr) were obtained postmortem and conserved as snap-frozen tissue blocks at the NeuroResource tissue bank, University College London Institute of Neurology (London, England, UK). Tissue collection for research purposes was authorized by the London Multi-Center Ethics committee (London, England, UK) and was performed after obtaining the informed consent form signed by a relative or appointed representative of the deceased donor. Both normal control white matter samples and MS chronic inactive plaques were from temporal, parietal, and occipital ventricular or subventricular regions.

Immunohistochemistry and immunofluorescence. 10- $\mu$ m-thick serial sections were cut from human snap-frozen CNS tissue blocks or from $4 \%$ paraformaldehyde (PFA)-perfused mouse spinal cords of four GFAP-cre: TrkBflox/flox and four TrkBflox/flox mice derived from two independent EAE experiments at day 18 after $M O_{35-55}$ peptide immunization. At least seven cervical, four thoracic, and three lumbar spinal cord sections were labeled for each mouse. Immunohistochemistry and immunofluorescence were performed as previously described (Berzi et al., 2008). The following antibodies were used: mouse $\alpha-T r k B-E C D$ (clone 72509; R\&D Systems), rabbit $\alpha$-TrkB full length (TK; Santa Cruz Biotechnology, Inc.), rabbit $\alpha$-TrkB truncated (T1; Santa Cruz Biotechnology, Inc.), rabbit $\alpha$-TrkB (Cell Signaling Technology), rat $\alpha$-TrkB (L30-1; Santa Cruz Biotechnology, Inc.), mouse $\alpha$-GFAP (clone 556327; BD), rabbit $\alpha$-GFAP (Dako), rat $\alpha$-GFAP (EMD), mouse $\alpha$-p75NTR (clone 74902; R\&D Systems), mouse $\alpha$-p75NTR (clone NGFR5; Invitrogen), mouse $\alpha$-p75NTR (clone C40-1457; BD), rabbit $\alpha$-p75NTR (Millipore), mouse $\alpha-\beta$-tubulin (Covance), rabbit $\alpha$-Nitrotyrosine, mouse $\alpha$-APP, mouse $\alpha$-CNPase, rabbit $\alpha-\beta$-galactosidase (all from Millipore), rat $\alpha-\mathrm{CD} 4$, rat $\alpha-\mathrm{CD} 19$, rat $\alpha-\mathrm{F} 4 / 80$ (all from eBioscience), and rabbit $\alpha$-iNOS (BD). As negative controls, mouse IgG1 (Sigma-Aldrich), rat IgG1 (BioLegend), or polyclonal rabbit Igs (Dako) were used at the same concentration as the primary antibodies. As secondary antibodies, horseradish peroxidase-labeled anti-mouse or anti-rabbit Ig (Envision system; Dako), followed by diaminobenzidine (DAB; Dako) reaction were used for immunohistochemistry, and Alexa Fluor 488-, Alexa Fluor $594-$, or Alexa Fluor 633-conjugated donkey or goat $\alpha$-mouse, $\alpha$-rabbit, or $\alpha$-rat IgGs (all from Invitrogen) were used for immunofluorescence. Preliminary experiments have been performed to determine the optimal antibody concentration, which gave negative controls but clear cell-associated positive stainings. Immunohistochemistry sections were counterstained with hematoxylin, and images were acquired using a light microscope (Axiophot; Carl Zeiss) equipped with $20 \times($ NA 0.50$)$ and $40 \times$ (NA 0.75) air objectives. Fluorescence images were captured with confocal laser-scanning microscopes equipped with $40 \times($ NA 1.30) and $60 \times($ NA 1.40) oil objectives (D-Eclipse C1; Nikon) or equipped with $40 \times($ NA 1.25) and $63 \times($ NA 1.20) oil objectives (TCS SP5; Leica). ImageProPlus 6.0 (Media Cybernetics) and ImageJ software (National Institutes of Health) were used for image analysis. The infiltration rate in the ventral white matter of the mouse spinal cord was calculated as the ratio in the number of $\mathrm{DAPI}^{+}$nuclei between EAE mice and naive mice per unit of area. The number of CD4, CD19, F4/80, and APPpositive cells was also calculated per unit of area. TrkB-T1 signal was quantified based on the number of TrkB-T1-positive pixels $/ \mathrm{mm}^{2}$ (arbitrary unit). Colocalization between GFAP and TrkB-T1 was calculated using ImageJ (Colocalization plug-in) and expressed as the percentage of colocalized pixels/ total GFAP-positive pixels.

Astrocyte culture, stimulation, and analysis. Human primary fetal astrocytes (Aloisi et al., 1992) were maintained in culture in DME-high glucose medium (Celbio-Euroclone) supplemented with $200 \mathrm{mM}$ L-glutamine (Celbio-Euroclone), $100 \mathrm{mM}$ sodium pyruvate (Celbio-Euroclone), antibiotics (1\% Pen-Strep solution; Celbio-Euroclone), and 10\% FCS (PAA; MMedical). Mouse primary astrocytes were prepared from newborn mice as described in Aloisi et al. (1998). Purity of human and mouse astrocyte cultures was checked by GFAP staining and was $>95 \%$. Treatment with 1-5-25 $\mathrm{ng} / \mathrm{ml}$ of human recombinant mature BDNF (PeproTech), $5 \mathrm{ng} / \mathrm{ml} \mathrm{NT}-3$ (Abcam), $5 \mathrm{ng} / \mathrm{ml} \mathrm{NT}-4$ (Abcam), and $10 \mathrm{ng} / \mathrm{ml} \mathrm{IL-1} \mathrm{(R \& D} \mathrm{Systems)} \mathrm{was}$ 
performed in serum-free medium. Supernatants were centrifuged $(330 \mathrm{~g}$, $5 \mathrm{~min}, 4^{\circ} \mathrm{C}$ ) to remove cell debris and stored at $-20^{\circ} \mathrm{C}$. If required, astrocytes were loaded with the NO dye DAF-FM (Invitrogen) and stimulated in phenol red-free DME (Invitrogen) medium. Loaded cells were either stimulated during time-lapse imaging or treated for $1.5 \mathrm{~h}$ and then fixed in $4 \%$ PFA and DAPI-stained in PBS/0.2\% Triton X-100. The number of NO-producing cells was calculated as the percentage of total DAPI-positive cells. At least 900 cells/treatment were analyzed. If required, $10 \mu \mathrm{M}$ L-NAME (Santa Cruz Biotechnology, Inc.), an NO inhibitor, was added together with stimuli.

RNA extraction, cDNA synthesis, and quantitative PCR. RNA from snap-frozen CNS tissue or from cultured astrocytes was extracted using Trireagent (Invitrogen) according to the manufacturer's instructions. cDNA was prepared using random hexamer primers and Superscript III reverse transcription (all from Invitrogen) according to the manufacturer's instructions. Real-time PCR was performed using TaqMan Universal Master Mix on the Gene AMP 7500 PCR platform (Applied Biosystems). Messenger RNA levels of target genes were graphically reported as the percentage of the housekeeping gene Cyclophilin A (PPIA). The amplification sets for human TrkB isoforms were previously reported (Berzi et al., 2008). Amplification sets for human PPIA and mouse GAPDH, mouse TrkB, and mouse p75NTR were purchased from Applied Biosystems.

Cytofluorometry. Human primary astrocytes were stained with mouse $\alpha$-TrkB-ECD (clone 72509; R\&D Systems) or isotype control (BD), followed by detection with Alexa Fluor 488-conjugated donkey $\alpha$-mouse secondary antibody (Invitrogen). p75NTR was stained with mouse $\alpha$-p75NTR PE conjugated (clone C40-1457; BD). Samples were analyzed using a FACSCalibur machine (BD).

Neuronal culture, stimulation, and analysis. Spinal primary mixed neurons were obtained from 16-d-old Sprague-Dawley rat embryos as described previously (Melli et al., 2006a,b). In brief, embryo spinal cords, depleted of spinal root ganglia, were dissected, carefully minced, and digested for $15 \mathrm{~min}$ at $37^{\circ} \mathrm{C}$ with $500 \mu \mathrm{g} / \mathrm{ml}$ DNAsi I (Roche) and $0.25 \%$ trypsin (Invitrogen) in L-15 medium (Invitrogen) supplemented with antibiotics. After digestion, the tissue homogenate was washed three times with L-15 medium and finally cultured in Neurobasal medium (Invitrogen) supplemented with $10 \mathrm{ng} / \mathrm{ml}$ of glial cell-derived neurotrophic factor GDNF (Sigma-Aldrich), $20 \mathrm{ng} / \mathrm{ml}$ fibroblast growth factor FGF (PeproTech), $5 \mu \mathrm{g} / \mathrm{ml}$ insulin (Sigma-Aldrich), B27 supplement (Invitrogen), 1\% FCS, and $10 \mathrm{mM}$ glucose. Cells were seeded on poly-lysine- and collagen (both from Sigma-Aldrich)-coated glass-inserted dishes (MatTek), on glass slides (Menzel), and/or on chamber slides (Nunc). After 24 h, $15 \mu \mathrm{M}$ cytosine b-D-arabinofuranoside (AraC; Sigma-Aldrich) was added to cultures and left for $4 \mathrm{~d}$ to eliminate contaminating microglia cells, astrocytes, and oligodendrocytes. After $1 \mathrm{~d}$ in AraC-free medium, neurons were exposed to ACM or recombinant factors for $24 \mathrm{~h}$. Then they were fixed with $4 \%$ PFA, permeabilized with $0.2 \%$ Triton X-100 in PBS, and blocked with $3 \%$ BSA in PBS. Staining with $2 \mu \mathrm{g} / \mathrm{ml}$ of monoclonal antibody $\alpha-\beta$ tubulin (Tuj1; Covance) and detection with donkey $\alpha$-mouse-IgG Alexa Fluor 594 antibody were performed. Finally, the green fluorimetric TUNEL reaction (DeadEnd fluorimetric TUNEL kit; Promega) was performed to label apoptotic nuclei according to the manufacturer's protocol, and all nuclei were stained with DAPI. Neuronal cultures were $100 \%$ pure, as all cells were $\beta$-tubulin positive. Neuronal fragmentation was quantified as loss in $\beta$-tubulin MFI compared with controls. The extent of apoptosis was quantified as the percentage of TUNEL-positive nuclei on all DAPIlabeled nuclei. At least 2,700 nuclei/treatment were analyzed. If necessary, $10 \mu \mathrm{M}$ L-NAME was added together with ACM. Images were acquired using an Axiophot fluorescence microscope equipped with 10× (NA 0.30), $20 \times($ NA 0.50), and $40 \times($ NA 0.75) air objectives or a CTR 5500 fluorescence microscope (Leica) equipped with $10 \times$ (NA 0.30) and $20 \times$ (NA $0.50)$ air objectives. ImageProPlus 6.0 software and Image software were used for analysis.
Treatment with anti-p75NTR or anti-BDNF blocking antibodies. Human astrocytes were exposed to serum-free medium supplemented with stimuli (25 ng/ml BDNF, $10 \mathrm{ng} / \mathrm{ml} \mathrm{IL1}$, or vehicle) in the presence of $10 \mu \mathrm{g} / \mathrm{ml}$ anti-human $\mathrm{p} 75 \mathrm{NTR}$ blocking monoclonal antibody (clone NGFR5; Invitrogen) or purified mouse IgG1 (BD). For BDNF blocking experiments, human astrocytes were exposed to serum-free medium added with stimuli (25 ng/ml BDNF, $10 \mathrm{ng} / \mathrm{ml} \mathrm{IL1}$, or vehicle) and $10 \mu \mathrm{g} / \mathrm{ml}$ anti-human BDNF polyclonal antibody (Millipore) or rabbit IgG (Jackson ImmunoResearch Laboratories, Inc.). Alternatively, neuronal cultures were exposed to ACM supplemented with BDNF blocking antibody or with the corresponding isotype control. For analysis, at least 1,800 nuclei/treatment were analyzed. All experiments included at least three technical replicates.

BDNF ELISA. BDNF levels were measured in human astrocyte supernatants with BDNF Emax ImmunoAssay System (Promega) according to the manufacturer's protocol. Colorimetric read-out was analyzed by Epoch Micro-Volume Spectrophotometer System (Biotek).

Live imaging. Rat primary neurons were monitored during treatment with either recombinant BDNF or ACM (sNT, sBDNF, or sIL1) by time-lapse DIC (differential interference contrast) imaging (one stack every 5 min) using a fluorescence microscope (Eclipse TE 2000-e; Nikon) equipped with a Q-imaging Fast Camera (Rolera MGi plus) and a temperature/ $\mathrm{CO}_{2}$ concentration control unit (OKOlab). Either $20 \times$ (NA 0.50) or 40× (NA 0.75) air objectives (Nikon) were used for live imaging acquisition. DAF-FMloaded astrocytes were monitored for NO production every 20 min starting from stimulation (time point 0 ). Both DIC and green fluorescence (excitation wavelength: $488 \mathrm{~nm}$, filter 450-490 nm; emission filter: $505 \mathrm{~nm}$ ) images were acquired using a $20 \times$ air objective. Video analysis was performed using NIS Elements AR software version 3.0 (Nikon) and ImageJ software.

Nitrite/nitrate production by human astrocytes. To quantify the amount of nitrites and nitrates in astrocyte supernatants, a total nitrite/nitrate colorimetric assay kit (Cayman Chemical) was used according to the manufacturer's protocol. Colorimetric read-out was analyzed via a Multiskan reader (Thermo Fisher Scientific).

Statistical analysis. Normality of the distribution was assessed by Kolmogorov-Smirnov statistics, and significance was measured by the Student's $t$ test with homeostatic variance in case of normal distribution or by MannWhitney $U$ test in case of non-normal distribution. For statistic evaluation of EAE clinical score, the nonparametric Mann-Whitney ranking $U$ test was used. All p-values were two-sided and subjected to a significance level of 0.05 .

Online supplemental material. Fig. S1 shows single frames of time-lapse imaging videos of neuronal cultures during treatment with ACM. Videos 1-3 show time-lapse imaging of neuronal cultures during treatment with ACM from astrocytes exposed to vehicle, IL-1, or BDNF, respectively. Video 4 shows time-lapse imaging of neuronal cultures exposed to recombinant BDNF. Videos 5-7 show time-lapse imaging of human primary astrocytes loaded with DAF-FM and exposed to vehicle, BDNF, or IL-1, respectively. Online supplemental material is available at http://www.jem .org/cgi/content/full/jem.20110698/DC1.

We are grateful to Prof. Hans Lassmann and Dr. Gianvito Martino for critical reading of the manuscript and to Prof. Giancarlo Comi, Dr. Marco Gentilini, and Amici Centro Sclerosi Multipla for support. We thank Dr. Gloria Invernici and Dr. Eugenio Agostino Parati for generation of human primary astrocytes.

This study was funded by Fondazione Italiana Sclerosi Multipla (FISM cod. 2007/R/5 to C. Farina). M. Krumbholz, R. Hohlfeld, and E. Meinl were supported by Deutsche Forschungsgemeinschaft (SFB 571) and Bundesministerium für Bildung und Forschung (KKNMS).

The authors have no conflicting financial interests.

Submitted: 8 April 2011

Accepted: 9 February 2012 


\section{REFERENCES}

Allendoerfer, K.L., R.J. Cabelli, E. Escandón, D.R. Kaplan, K. Nikolics, and C.J. Shatz. 1994. Regulation of neurotrophin receptors during the maturation of the mammalian visual system. J. Neurosci. 14:1795-1811.

Aloisi, F., G. Borsellino, P. Samoggia, U. Testa, C. Chelucci, G. Russo, C. Peschle, and G. Levi. 1992. Astrocyte cultures from human embryonic brain: characterization and modulation of surface molecules by inflammatory cytokines. J. Neurosci. Res. 32:494-506. http://dx.doi .org/10.1002/jnr.490320405

Aloisi, F., F. Ria, G. Penna, and L. Adorini. 1998. Microglia are more efficient than astrocytes in antigen processing and in Th1 but not Th2 cell activation. J. Immunol. 160:4671-4680.

Azoulay, D., V. Vachapova, B. Shihman, A. Miler, and A. Karni. 2005. Lower brain-derived neurotrophic factor in serum of relapsing remitting MS: reversal by glatiramer acetate. J. Neuroimmunol. 167:215-218. http://dx.doi.org/10.1016/j.jneuroim.2005.07.001

Azoulay, D., N. Urshansky, and A. Karni. 2008. Low and dysregulated BDNF secretion from immune cells of MS patients is related to reduced neuroprotection. J. Neuroimmunol. 195:186-193. http://dx.doi .org/10.1016/j.jneuroim.2008.01.010

Azoulay, D., K. Mausner-Fainberg, N. Urshansky, F. Fahoum, and A. Karni. 2009. Interferon-beta therapy up-regulates BDNF secretion from PBMCs of MS patients through a CD40-dependent mechanism. J. Neuroimmunol. 211:114-119. http://dx.doi.org/10.1016/j.jneuroim.2009.04.004

Baxter, G.T., M.J. Radeke, R.C. Kuo, V. Makrides, B. Hinkle, R. Hoang, A. Medina-Selby, D. Coit, P. Valenzuela, and S.C. Feinstein. 1997. Signal transduction mediated by the truncated trkB receptor isoforms, trkB.T1 and trkB.T2. J. Neurosci. 17:2683-2690.

Berzi, A., C.K. Ayata, P. Cavalcante, C. Falcone, E. Candiago, T. Motta, P. Bernasconi, R. Hohlfeld, R. Mantegazza, E. Meinl, and C. Farina. 2008. BDNF and its receptors in human myasthenic thymus: Implications for cell fate in thymic pathology. J. Neuroimmunol. 197:128-139. http:// dx.doi.org/10.1016/j.jneuroim.2008.04.019

Binder, D.K., and H.E. Scharfman. 2004. Brain-derived neurotrophic factor. Growth Factors. 22:123-131. http://dx.doi.org/10.1080/ 08977190410001723308

Blackburn, D., S. Sargsyan, P.N. Monk, and P.J. Shaw. 2009. Astrocyte function and role in motor neuron disease: A future therapeutic target? Glia. 57:1251-1264. http://dx.doi.org/10.1002/glia.20848

Brambilla, R., V. Bracchi-Ricard, W.H. Hu, B. Frydel, A. Bramwell, S. Karmally, E.J. Green, and J.R. Bethea. 2005. Inhibition of astroglial nuclear factor $\mathrm{\kappa B}$ reduces inflammation and improves functional recovery after spinal cord injury. J. Exp. Med. 202:145-156. http://dx.doi .org/10.1084/jem.20041918

Brambilla, R., A. Hurtado, T. Persaud, K. Esham, D.D. Pearse, M. Oudega, and J.R. Bethea. 2009a. Transgenic inhibition of astroglial NF-kappa $\mathrm{B}$ leads to increased axonal sparing and sprouting following spinal cord injury. J. Neurochem. 110:765-778. http://dx.doi.org/10.1111/j.14714159.2009.06190.x

Brambilla, R., T. Persaud, X. Hu, S. Karmally, V.I. Shestopalov, G. Dvoriantchikova, D. Ivanov, L. Nathanson, S.R. Barnum, and J.R. Bethea. 2009b. Transgenic inhibition of astroglial NF-kappa B improves functional outcome in experimental autoimmune encephalomyelitis by suppressing chronic central nervous system inflammation. J. Immunol. 182:2628-2640. http://dx.doi.org/10.4049/ jimmunol.0802954

Brorson, J.R., P.T. Schumacker, and H. Zhang. 1999. Nitric oxide acutely inhibits neuronal energy production. The Committees on Neurobiology and Cell Physiology. J. Neurosci. 19:147-158.

Brown, G.C., and A. Bal-Price. 2003. Inflammatory neurodegeneration mediated by nitric oxide, glutamate, and mitochondria. Mol. Neurobiol. 27:325-355. http://dx.doi.org/10.1385/MN:27:3:325

Cai, J., Y. Chen, W.H. Cai, E.C. Hurlock, H. Wu, S.G. Kernie, L.F. Parada, and Q.R. Lu. 2007. A crucial role for Olig2 in white matter astrocyte development. Development. 134:1887-1899. http://dx.doi.org/10.1242/dev.02847

Calabrese, V., C. Mancuso, M. Calvani, E. Rizzarelli, D.A. Butterfield, and A.M. Stella. 2007. Nitric oxide in the central nervous system: Neuroprotection versus neurotoxicity. Nat. Rev. Neurosci. 8:766-775. http://dx.doi.org/10.1038/nrn2214
Cohen, S., and M.E. Greenberg. 2008. Communication between the synapse and the nucleus in neuronal development, plasticity, and disease. Annu. Rev. Cell Dev. Biol. 24:183-209. http://dx.doi.org/10.1146/ annurev.cellbio.24.110707.175235

Colombo, E., S. Romaggi, F. Blasevich, M. Mora, C. Falcone, H. Lochmüller, L. Morandi, and C. Farina. 2011a. The neurotrophin receptor p75NTR is induced on mature myofibres in inflammatory myopathies and promotes myotube survival to inflammatory stress. Neuropathol. Appl. Neurobiol. http://dx.doi.org/10.1111/J.1365-2990 .2011.01212.x

Colombo, E., S. Romaggi, E. Medico, R. Menon, M. Mora, C. Falcone, H. Lochmüller, P. Confalonieri, R. Mantegazza, L. Morandi, and C. Farina. 2011b. Human neurotrophin receptor p75NTR defines differentiation-oriented skeletal muscle precursor cells: implications for muscle regeneration. J. Neuropathol. Exp. Neurol. 70:133-142. http:// dx.doi.org/10.1097/NEN.0b013e3182084391

Cordiglieri, C., and C. Farina. 2010. Astrocytes exert and control immune responses in the brain. Curr. Immunol. Rev. 6:150-159. http://dx.doi .org/10.2174/157339510791823655

Cross, A.H., P.T. Manning, M.K. Stern, and T.P. Misko. 1997. Evidence for the production of peroxynitrite in inflammatory CNS demyelination. J. Neuroimmunol. 80:121-130. http://dx.doi.org/10.1016/ S0165-5728(97)00145-8

Dorsey, S.G., L.L. Bambrick, R.J. Balice-Gordon, and B.K. Krueger. 2002. Failure of brain-derived neurotrophic factor-dependent neuron survival in mouse trisomy 16. J. Neurosci. 22:2571-2578.

Dorsey, S.G., C.L. Renn, L. Carim-Todd, C.A. Barrick, L. Bambrick, B.K Krueger, C.W. Ward, and L. Tessarollo. 2006. In vivo restoration of physiological levels of truncated TrkB.T1 receptor rescues neuronal cell death in a trisomic mouse model. Neuron. 51:21-28. http://dx.doi .org/10.1016/j.neuron.2006.06.009

Dowling, P., X. Ming, S. Raval, W. Husar, P. Casaccia-Bonnefil, M. Chao, S. Cook, and B. Blumberg. 1999. Up-regulated p75NTR neurotrophin receptor on glial cells in MS plaques. Neurology. 53 1676-1682.

Dvoriantchikova, G., D. Barakat, R. Brambilla, C. Agudelo, E. Hernandez, J.R. Bethea, V.I. Shestopalov, and D. Ivanov. 2009. Inactivation of astroglial NF-kappa B promotes survival of retinal neurons following ischemic injury. Eur. J. Neurosci. 30:175-185. http://dx.doi .org/10.1111/j.1460-9568.2009.06814.x

Farina, C., F. Aloisi, and E. Meinl. 2007. Astrocytes are active players in cerebral innate immunity. Trends Immunol. 28:138-145. http://dx.doi .org/10.1016/j.it.2007.01.005

Friedman, W.J. 2000. Neurotrophins induce death of hippocampal neurons via the p75 receptor. J. Neurosci. 20:6340-6346.

Frisén, J., V.M. Verge, K. Fried, M. Risling, H. Persson, J. Trotter, T. Hökfelt, and D. Lindholm. 1993. Characterization of glial trkB receptors: differential response to injury in the central and peripheral nervous systems. Proc. Natl. Acad. Sci. USA. 90:4971-4975. http://dx.doi.org/ 10.1073/pnas.90.11.4971

Fu, E.S., Y.P. Zhang, J. Sagen, K.A. Candiotti, P.D. Morton, D.J. Liebl, J.R. Bethea, and R. Brambilla. 2010. Transgenic inhibition of glial NFkappa B reduces pain behavior and inflammation after peripheral nerve injury. Pain. 148:509-518. http://dx.doi.org/10.1016/j.pain. 2010.01.001

Graumann, U., R. Reynolds, A.J. Steck, and N. Schaeren-Wiemers. 2003. Molecular changes in normal appearing white matter in multiple sclerosis are characteristic of neuroprotective mechanisms against hypoxic insult. Brain Pathol. 13:554-573. http://dx.doi.org/10.1111/j.17503639.2003.tb00485.x

Haroon, F., K. Drögemüller, U. Händel, A. Brunn, D. Reinhold, G. Nishanth, W. Mueller, C. Trautwein, M. Ernst, M. Deckert, and D. Schlüter. 2011. Gp130-dependent astrocytic survival is critical for the control of autoimmune central nervous system inflammation. J. Immunol. 186:6521-6531. http://dx.doi.org/10.4049/jimmunol.1001135

Holley, J.E., D. Gveric, J. Newcombe, M.L. Cuzner, and N.J. Gutowski. 2003. Astrocyte characterization in the multiple sclerosis glial scar. Neuropathol. Appl. Neurobiol. 29:434-444. http://dx.doi.org/10.1046/ j.1365-2990.2003.00491.x 
Huang, E.J., and L.F. Reichardt. 2003. Trk receptors: Roles in neuronal signal transduction. Annu. Rev. Biochem. 72:609-642. http://dx.doi.org/ 10.1146/annurev.biochem.72.121801.161629

Jack, C., J. Antel, W. Brück, and T. Kuhlmann. 2007. Contrasting potential of nitric oxide and peroxynitrite to mediate oligodendrocyte injury in multiple sclerosis. Glia. 55:926-934. http://dx.doi.org/ 10.1002/glia.20514

Javeri, S., M. Rodi, M. Tary-Lehmann, P.V. Lehmann, K. Addicks, and S. Kuerten. 2010. Involvement of brain-derived neurotrophic factor (BDNF) in MP4-induced autoimmune encephalomyelitis. Clin. Immunol. 137:181-189. http://dx.doi.org/10.1016/j.clim.2010.08.001

Kerschensteiner, M., M.E. Schwab, J.W. Lichtman, and T. Misgeld. 2005. In vivo imaging of axonal degeneration and regeneration in the injured spinal cord. Nat. Med. 11:572-577. http://dx.doi.org/10.1038/nm1229

Korte, M., P. Carroll, E. Wolf, G. Brem, H. Thoenen, and T. Bonhoeffer. 1995. Hippocampal long-term potentiation is impaired in mice lacking brain-derived neurotrophic factor. Proc. Natl. Acad. Sci. USA. 92:88568860. http://dx.doi.org/10.1073/pnas.92.19.8856

Linker, R.A., D.H. Lee, S. Demir, S. Wiese, N. Kruse, I. Siglienti, E. Gerhardt, H. Neumann, M. Sendtner, F. Lühder, and R. Gold. 2010. Functional role of brain-derived neurotrophic factor in neuroprotective autoimmunity: Therapeutic implications in a model of multiple sclerosis. Brain. 133:2248-2263. http://dx.doi.org/10.1093/brain/awq179

Liu, J.S., M.L. Zhao, C.F. Brosnan, and S.C. Lee. 2001. Expression of inducible nitric oxide synthase and nitrotyrosine in multiple sclerosis lesions. Am. J. Pathol. 158:2057-2066. http://dx.doi.org/10.1016/ S0002-9440(10)64677-9

Luikart, B.W., S. Nef, T. Virmani, M.E. Lush, Y. Liu, E.T. Kavalali, and L.F Parada. 2005. TrkB has a cell-autonomous role in the establishment of hippocampal Schaffer collateral synapses. J. Neurosci. 25:3774-3786. http://dx.doi.org/10.1523/JNEUROSCI.0041-05.2005

Mahad, D., I. Ziabreva, H. Lassmann, and D. Turnbull. 2008. Mitochondrial defects in acute multiple sclerosis lesions. Brain. 131:1722-1735. http:// dx.doi.org/10.1093/brain/awn105

Malatesta, P., M.A. Hack, E. Hartfuss, H. Kettenmann, W. Klinkert, F. Kirchhoff, and M. Götz. 2003. Neuronal or glial progeny: Regional differences in radial glia fate. Neuron. 37:751-764. http://dx.doi.org/ 10.1016/S0896-6273(03)00116-8

Melli, G., C. Jack, G.L. Lambrinos, M. Ringkamp, and A. Höke. 2006a. Erythropoietin protects sensory axons against paclitaxel-induced distal degeneration. Neurobiol. Dis. 24:525-530. http://dx.doi.org/ 10.1016/j.nbd.2006.08.014

Melli, G., S.C. Keswani, A. Fischer, W. Chen, and A. Höke. 2006b. Spatially distinct and functionally independent mechanisms of axonal degeneration in a model of HIV-associated sensory neuropathy. Brain. 129:1330-1338. http://dx.doi.org/10.1093/brain/awl058

Mycko, M.P., R. Papoian, U. Boschert, C.S. Raine, and K.W. Selmaj. 2004. Microarray gene expression profiling of chronic active and inactive lesions in multiple sclerosis. Clin. Neurol. Neurosurg. 106:223-229. http://dx.doi.org/10.1016/j.clineuro.2004.02.019

Ohira, K., K. Shimizu, and M. Hayashi. 1999. Change of expression of full-length and truncated TrkBs in the developing monkey central nervous system. Brain Res. Dev. Brain Res. 112:21-29. http://dx.doi.org/ 10.1016/S0165-3806(98)00151-5
Ohira, K., H. Kumanogoh, Y. Sahara, K.J. Homma, H. Hirai, S Nakamura, and M. Hayashi. 2005. A truncated tropomyosin-related kinase $\mathrm{B}$ receptor, T1, regulates glial cell morphology via Rho GDP dissociation inhibitor 1. J. Neurosci. 25:1343-1353. http://dx.doi.org/ 10.1523/JNEUROSCI.4436-04.2005

Pacher, P., J.S. Beckman, and L. Liaudet. 2007. Nitric oxide and peroxynitrite in health and disease. Physiol. Rev. 87:315-424. http://dx.doi.org/ 10.1152/physrev.00029.2006

Petratos, S., M.F. Gonzales, M.F. Azari, M. Marriott, R.A. Minichiello, K.A. Shipham, C. Profyris, A. Nicolaou, K. Boyle, S.S. Cheema, and T.J. Kilpatrick. 2004. Expression of the low-affinity neurotrophin receptor, $\mathrm{p} 75$ (NTR), is upregulated by oligodendroglial progenitors adjacent to the subventricular zone in response to demyelination. Glia. 48:64-75. http://dx.doi.org/10.1002/glia.20056

Reichardt, L.F. 2006. Neurotrophin-regulated signalling pathways. Philos. Trans. R.Soc.Lond.BBiol.Sci.361:1545-1564.http://dx.doi.org/10.1098/ rstb.2006.1894

Rose, C.R., R. Blum, B. Pichler, A. Lepier, K.W. Kafitz, and A. Konnerth. 2003. Truncated TrkB-T1 mediates neurotrophin-evoked calcium signalling in glia cells. Nature. 426:74-78. http://dx.doi.org/ 10.1038/nature01983

Sarchielli, P., M. Zaffaroni, A. Floridi, L. Greco, A. Candeliere, A. Mattioni, S. Tenaglia, M. Di Filippo, and P. Calabresi. 2007. Production of brainderived neurotrophic factor by mononuclear cells of patients with multiple sclerosis treated with glatiramer acetate, interferon-beta $1 \mathrm{a}$, and high doses of immunoglobulins. Mult. Scler. 13:313-331. http://dx.doi .org/10.1177/1352458506070146

Sofroniew, M.V. 2009. Molecular dissection of reactive astrogliosis and glial scar formation. Trends Neurosci. 32:638-647. http://dx.doi.org/ 10.1016/j.tins.2009.08.002

Stadelmann, C., M. Kerschensteiner, T. Misgeld, W. Brück, R. Hohlfeld, and H. Lassmann. 2002. BDNF and gp145trkB in multiple sclerosis brain lesions: Neuroprotective interactions between immune and neuronal cells? Brain. 125:75-85. http://dx.doi.org/10.1093/brain/awf015

Stoilov, P., E. Castren, and S. Stamm. 2002. Analysis of the human TrkB gene genomic organization reveals novel TrkB isoforms, unusual gene length, and splicing mechanism. Biochem. Biophys. Res. Commun. 290: 1054-1065. http://dx.doi.org/10.1006/bbrc.2001.6301

Trapp, B.D., and P.K. Stys. 2009. Virtual hypoxia and chronic necrosis of demyelinated axons in multiple sclerosis. Lancet Neurol. 8:280-291. http://dx.doi.org/10.1016/S1474-4422(09)70043-2

Wang, Y., C. Hagel, W. Hamel, S. Müller, L. Kluwe, and M. Westphal. 1998. Trk A, B, and C are commonly expressed in human astrocytes and astrocytic gliomas but not by human oligodendrocytes and oligodendroglioma. Acta Neuropathol. 96:357-364. http://dx.doi.org/ 10.1007/s004010050906

Widenfalk, J., K. Lundströmer, M. Jubran, S. Brene, and L. Olson. 2001. Neurotrophic factors and receptors in the immature and adult spinal cord after mechanical injury or kainic acid. J. Neurosci. 21:3457-3475.

Wong, S.T., J.R. Henley, K.C. Kanning, K.H. Huang, M. Bothwell, and M.M. Poo. 2002. A p75(NTR) and Nogo receptor complex mediates repulsive signaling by myelin-associated glycoprotein. Nat. Neurosci. 5:1302-1308. http://dx.doi.org/10.1038/nn975 